\title{
Construction of the Fused Pentacycle of Talatisamine via a Combination of Radical and Cationic Cyclizations
}

Toshiki Tabuchi, Daisuke Urabe and Masayuki Inoue*

Graduate School of Pharmaceutical Sciences

The University of Tokyo, Hongo, Bunkyo-ku, Tokyo 113-0033, Japan

Fax: (+81)3-5841-0568

E-mail: inoue@mol.f.u-tokyo.ac.jp

Supporting Information

21 pages

Contents:

page

${ }^{1} \mathrm{H}$ and ${ }^{13} \mathrm{C}$ NMR spectra of newly synthesized compounds

S2

$\mathrm{X}$-ray structure and crystallographic data of compound $\mathbf{2 5}$

S20 


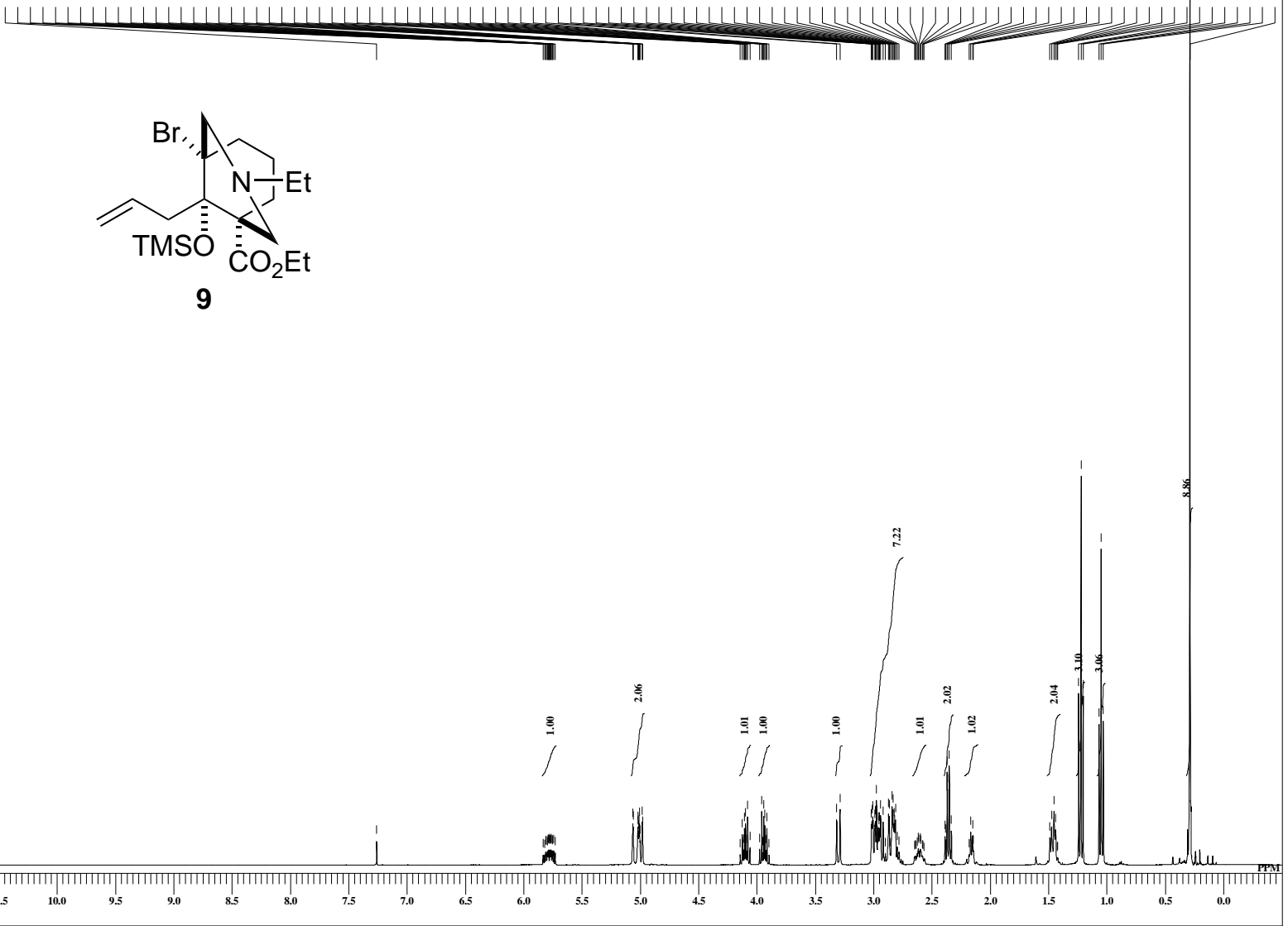

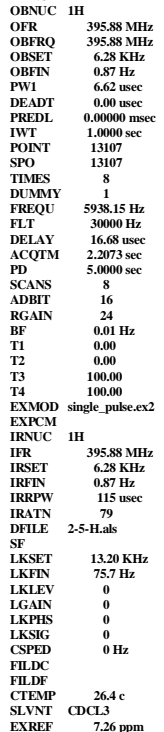
EXREF ${ }_{7.26 \mathrm{ppn}}$

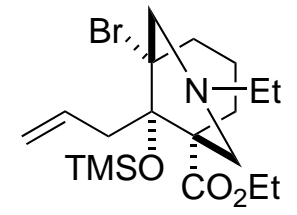

9

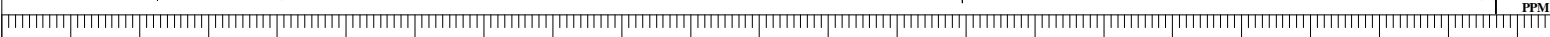

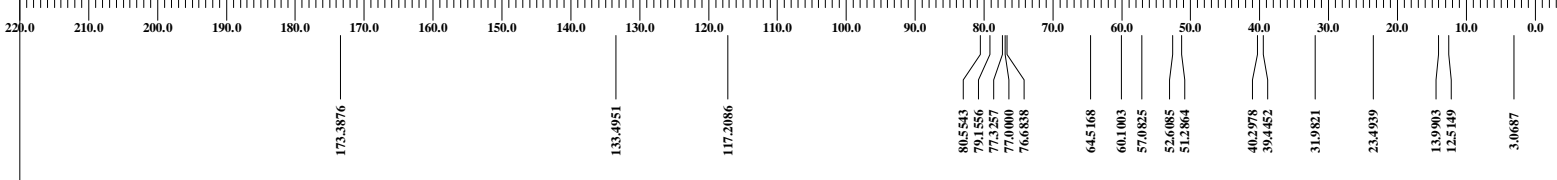


2-6
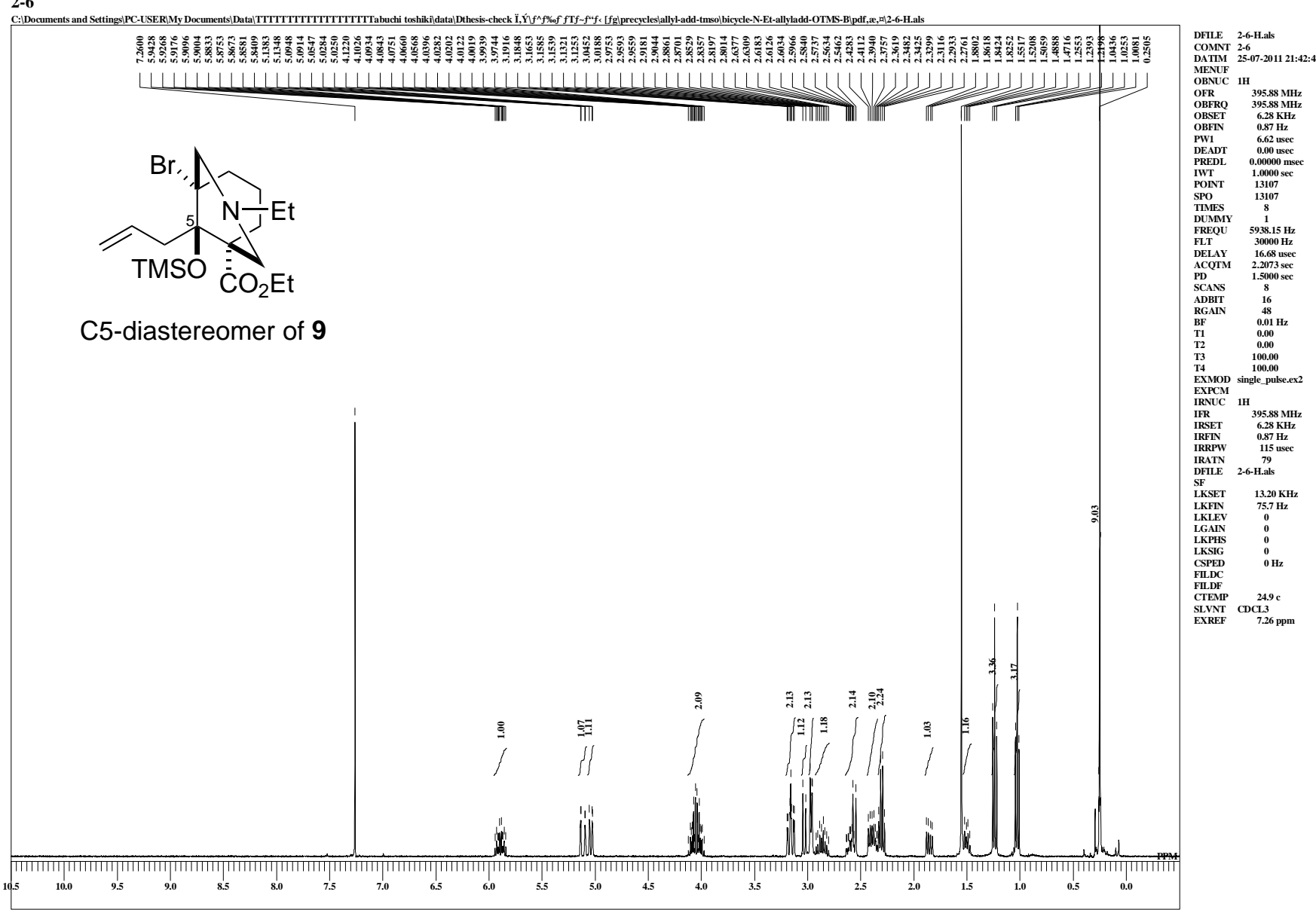

2-6

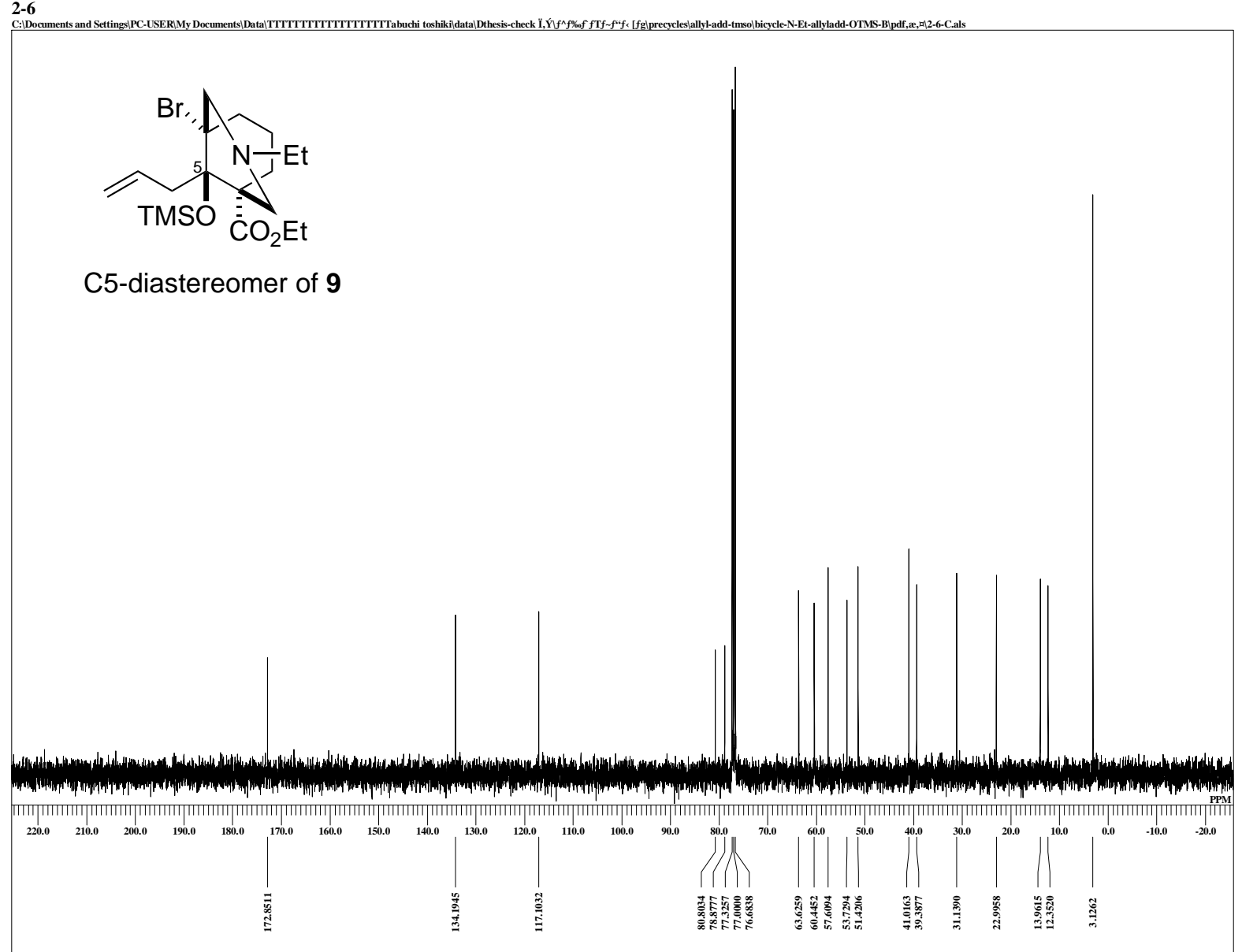


$2-43$

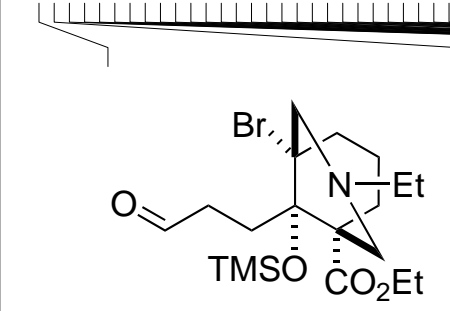

11

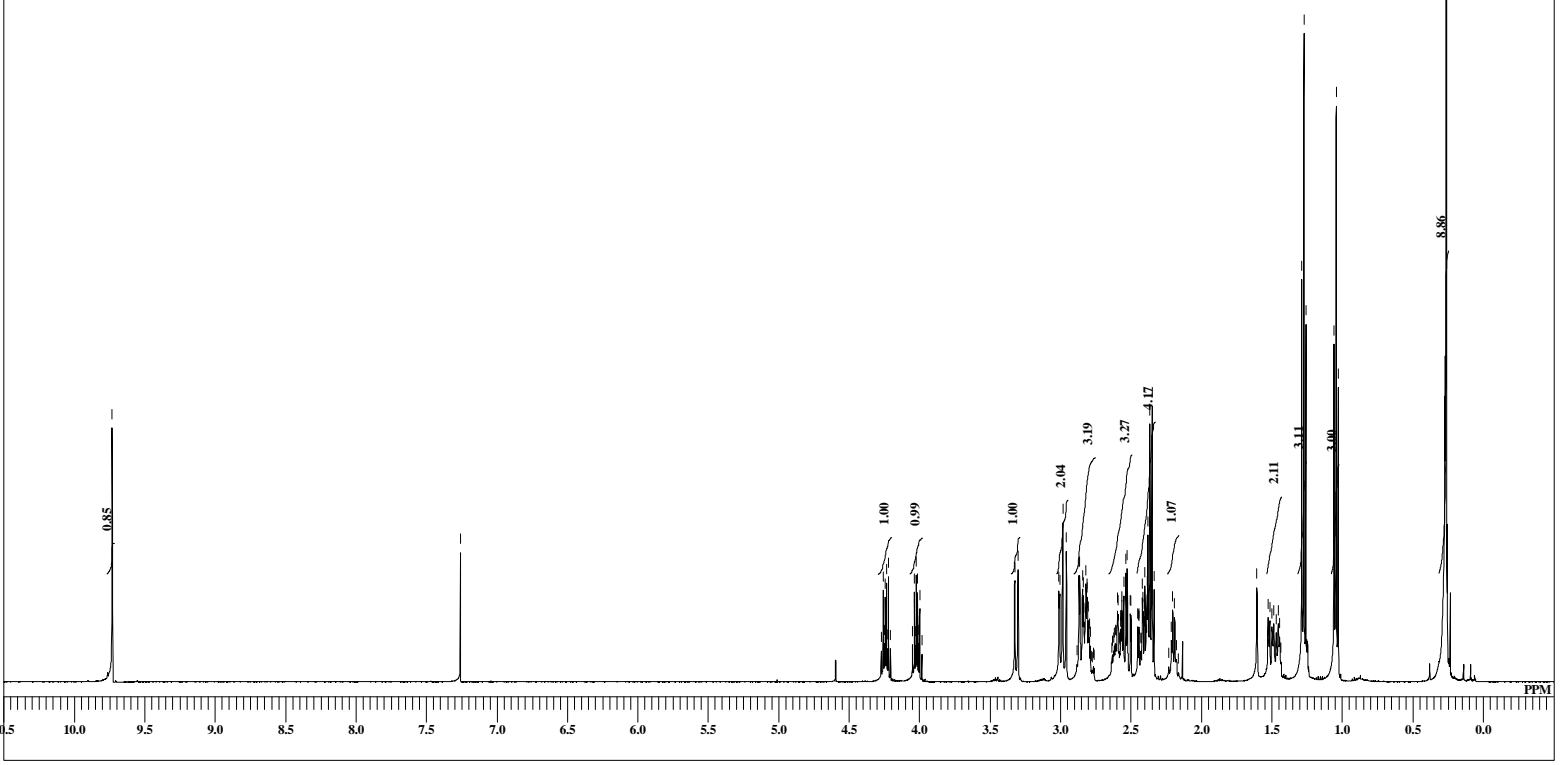

2-43

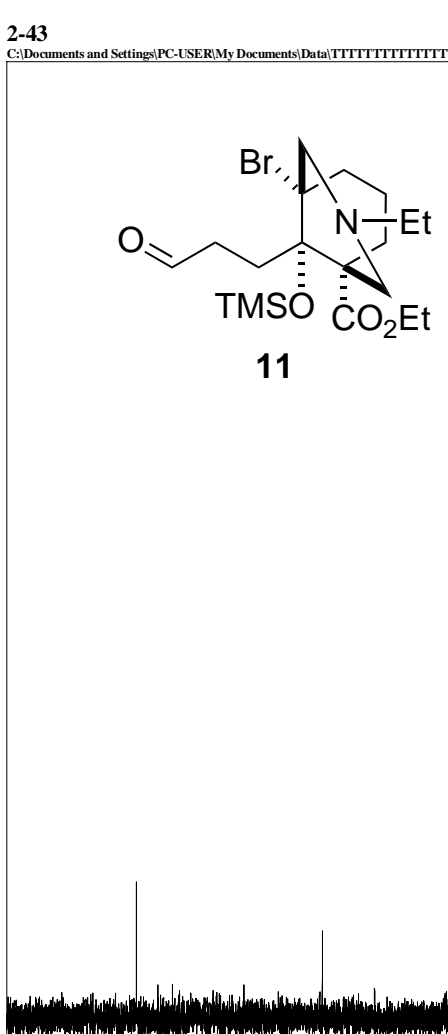

11

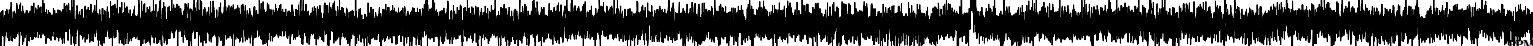

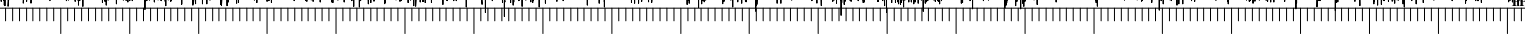

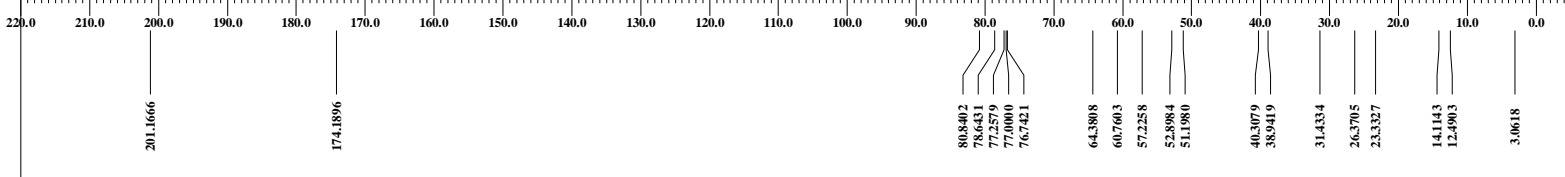



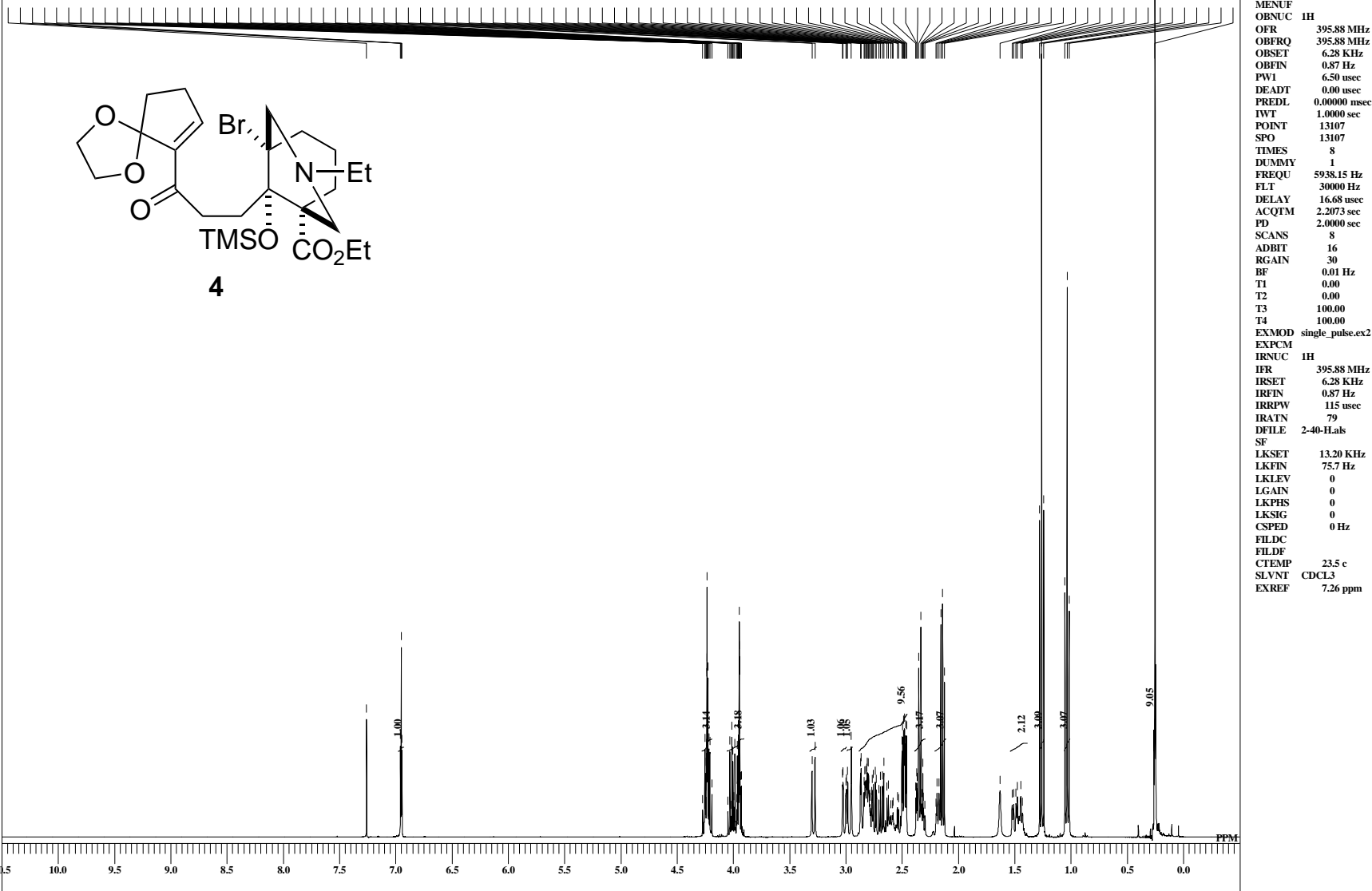

2-40
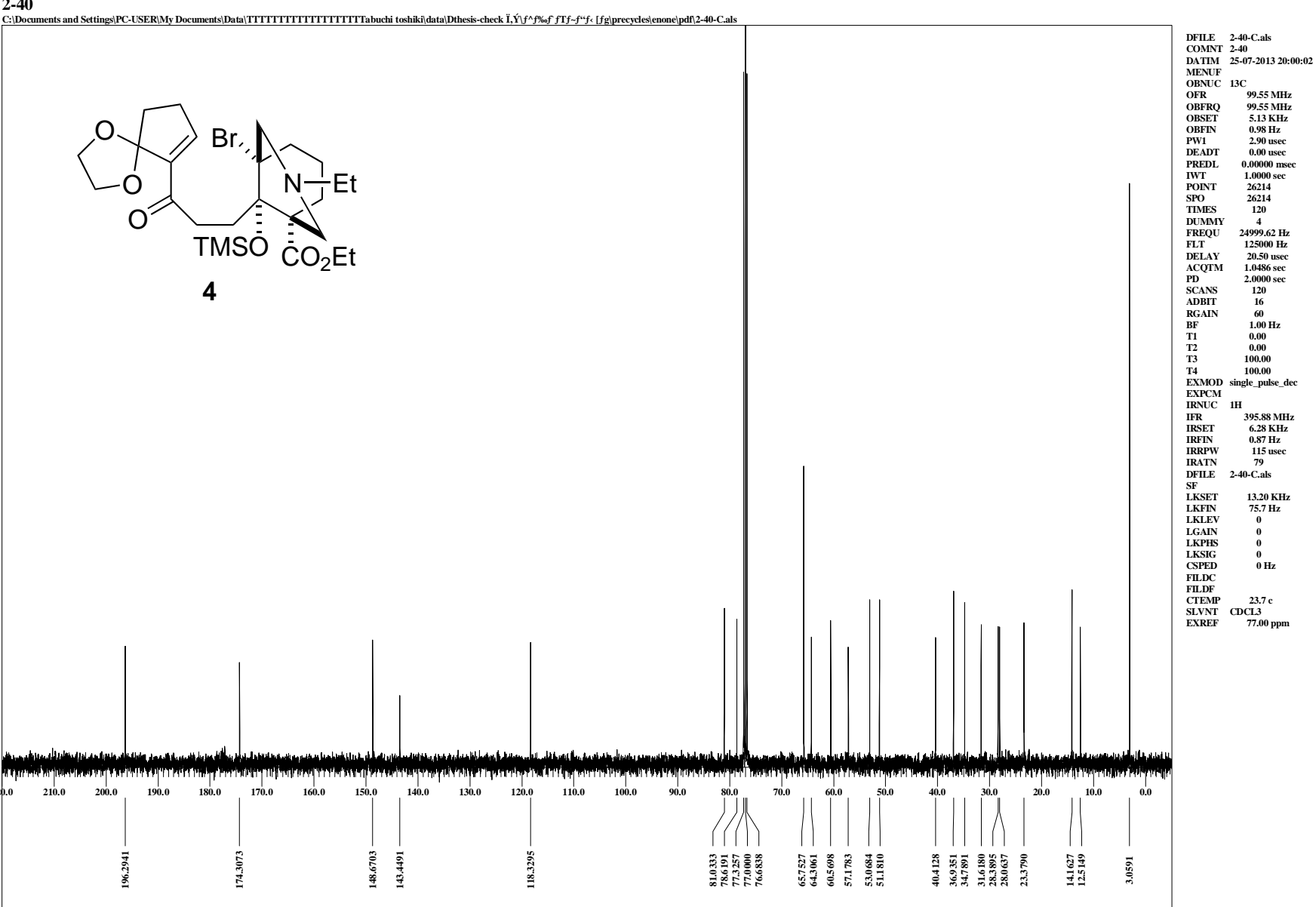

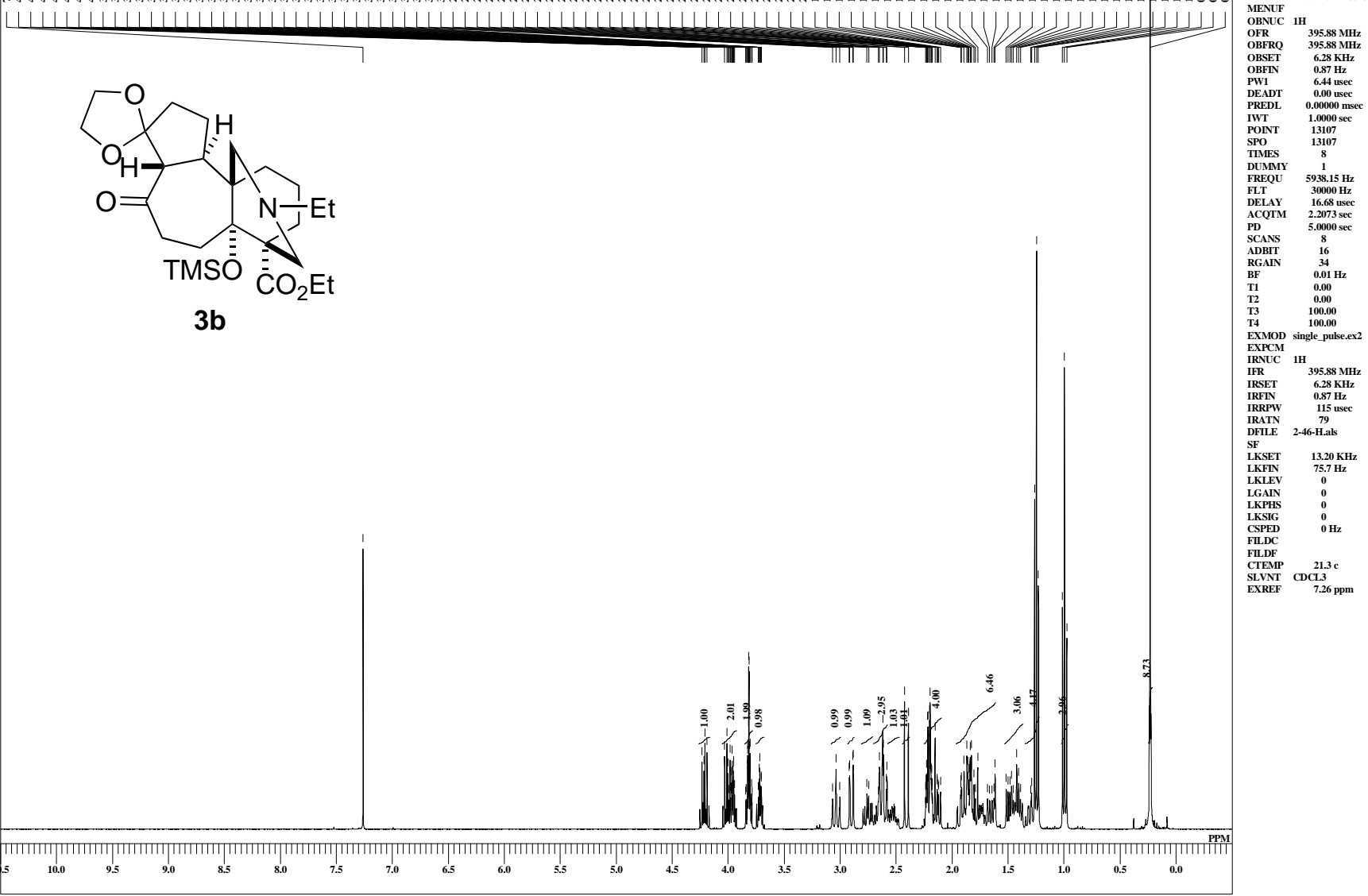

$2-46$

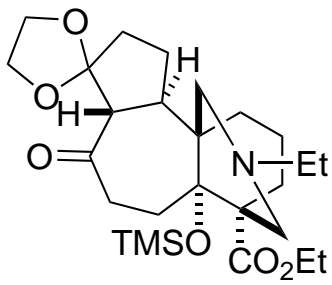

3b

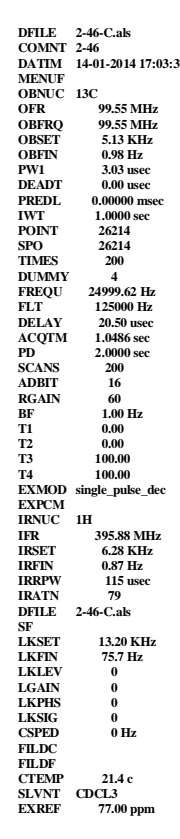

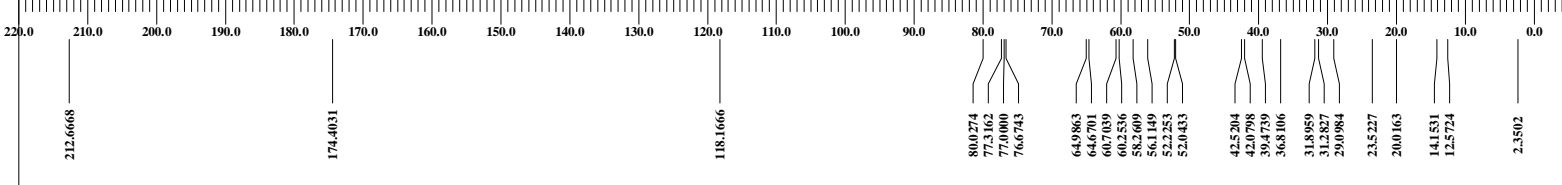


2-45
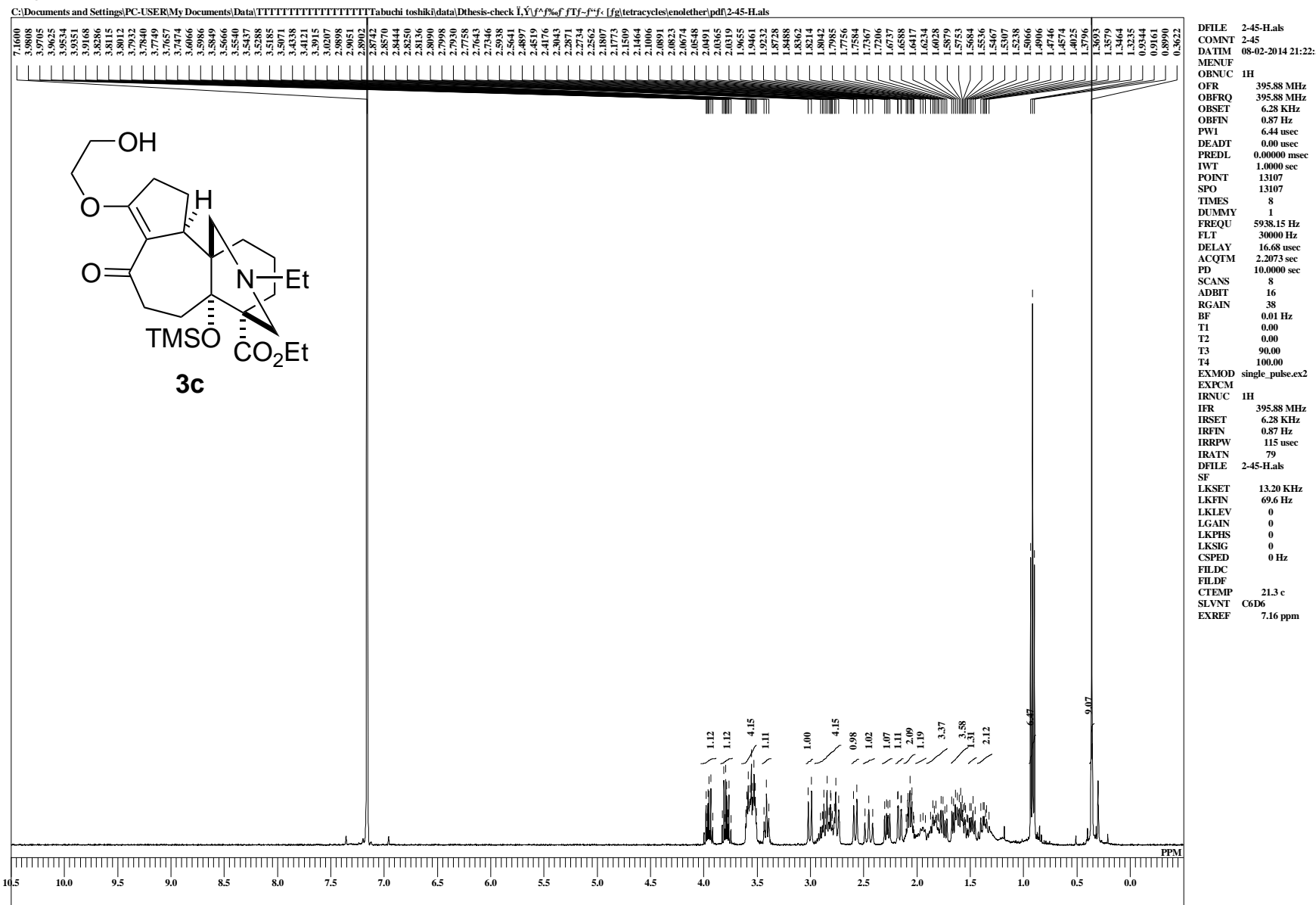

2-45

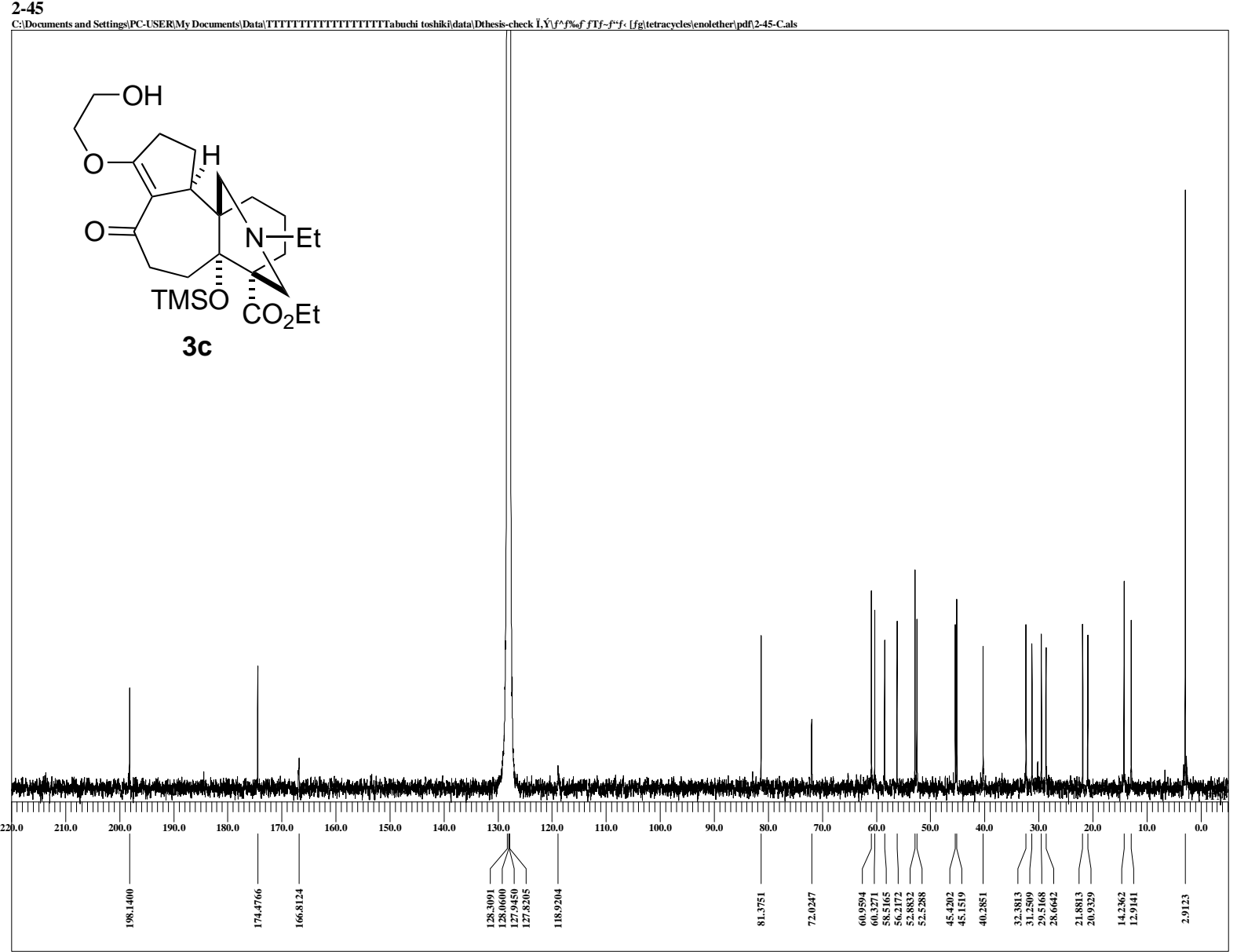



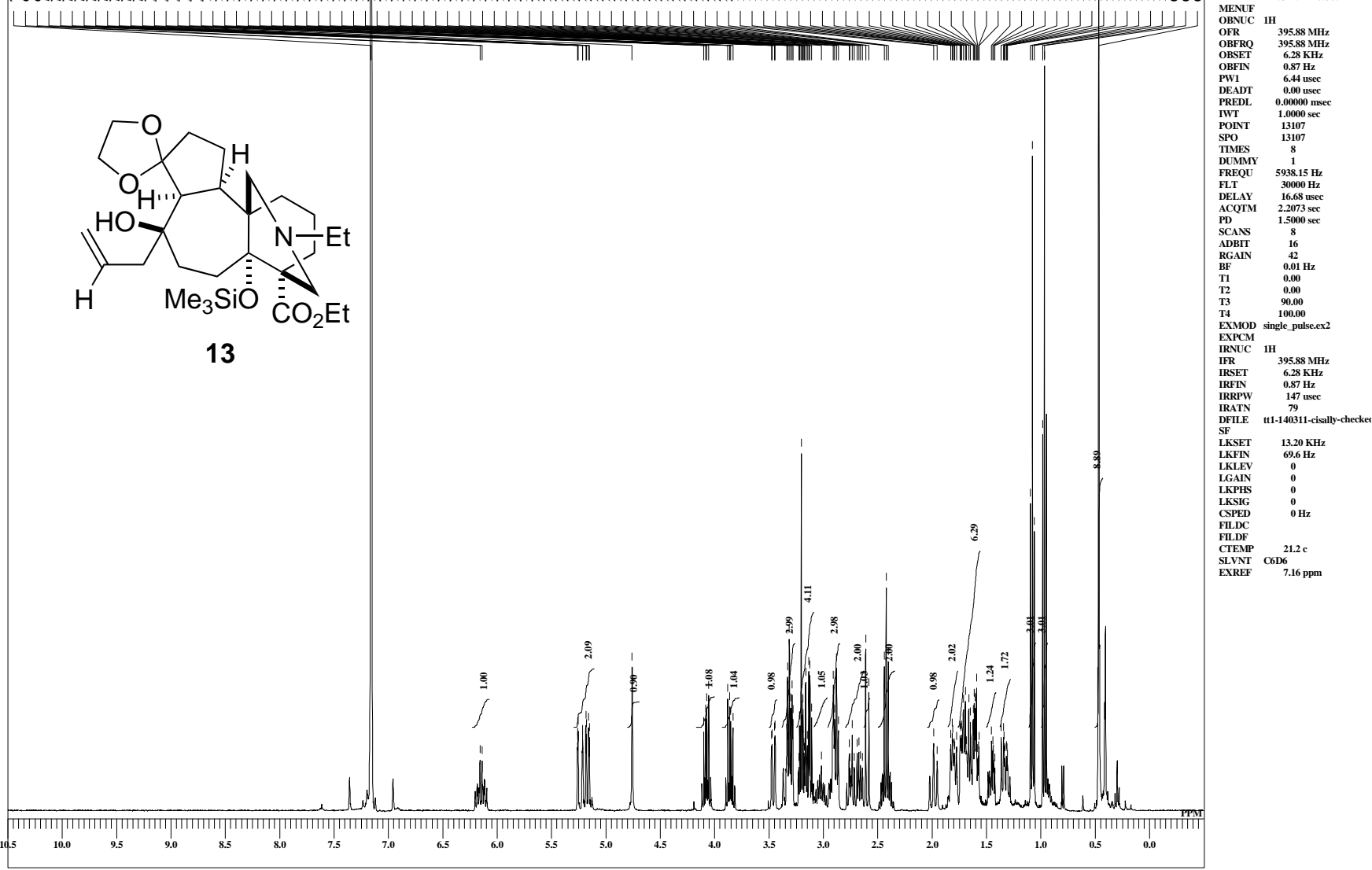

TT1-140311-cisallyl-C

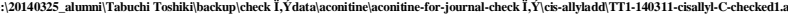

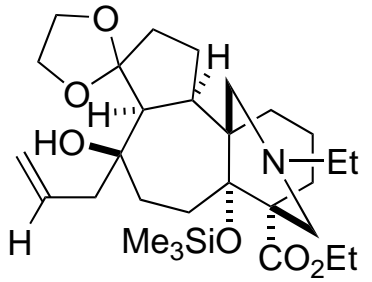

13

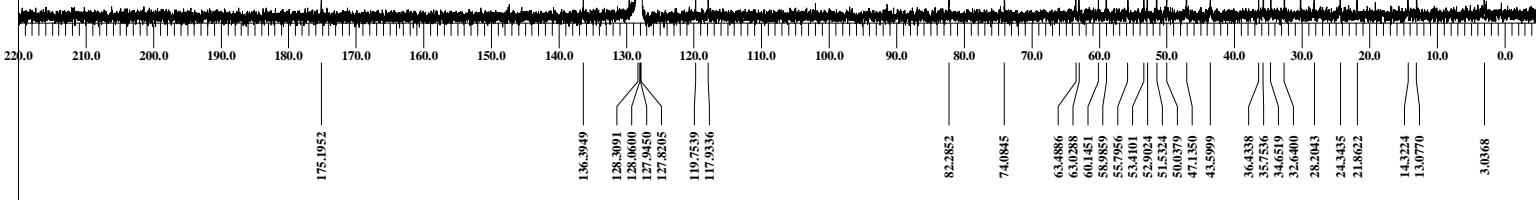


3-34

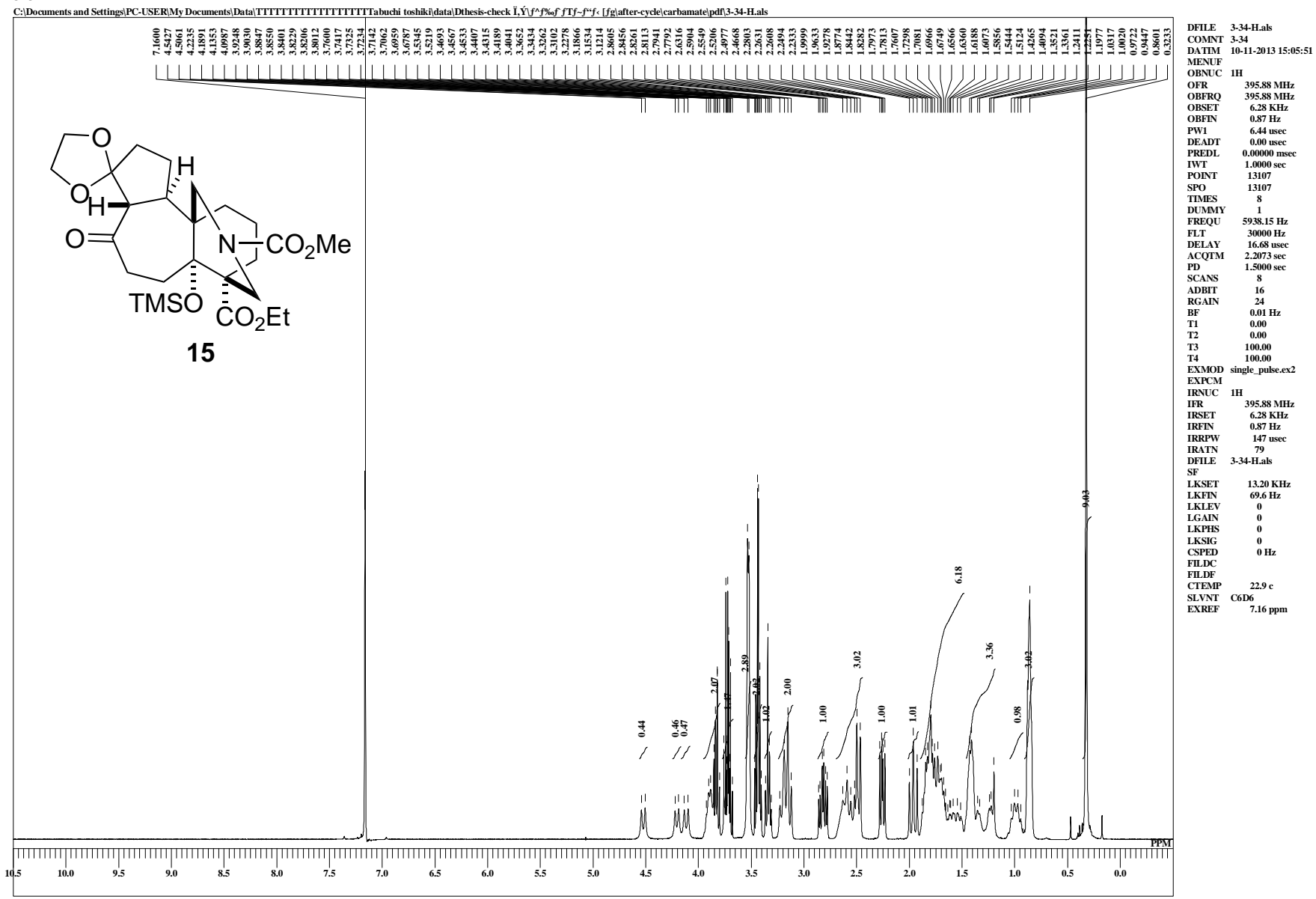

3-34

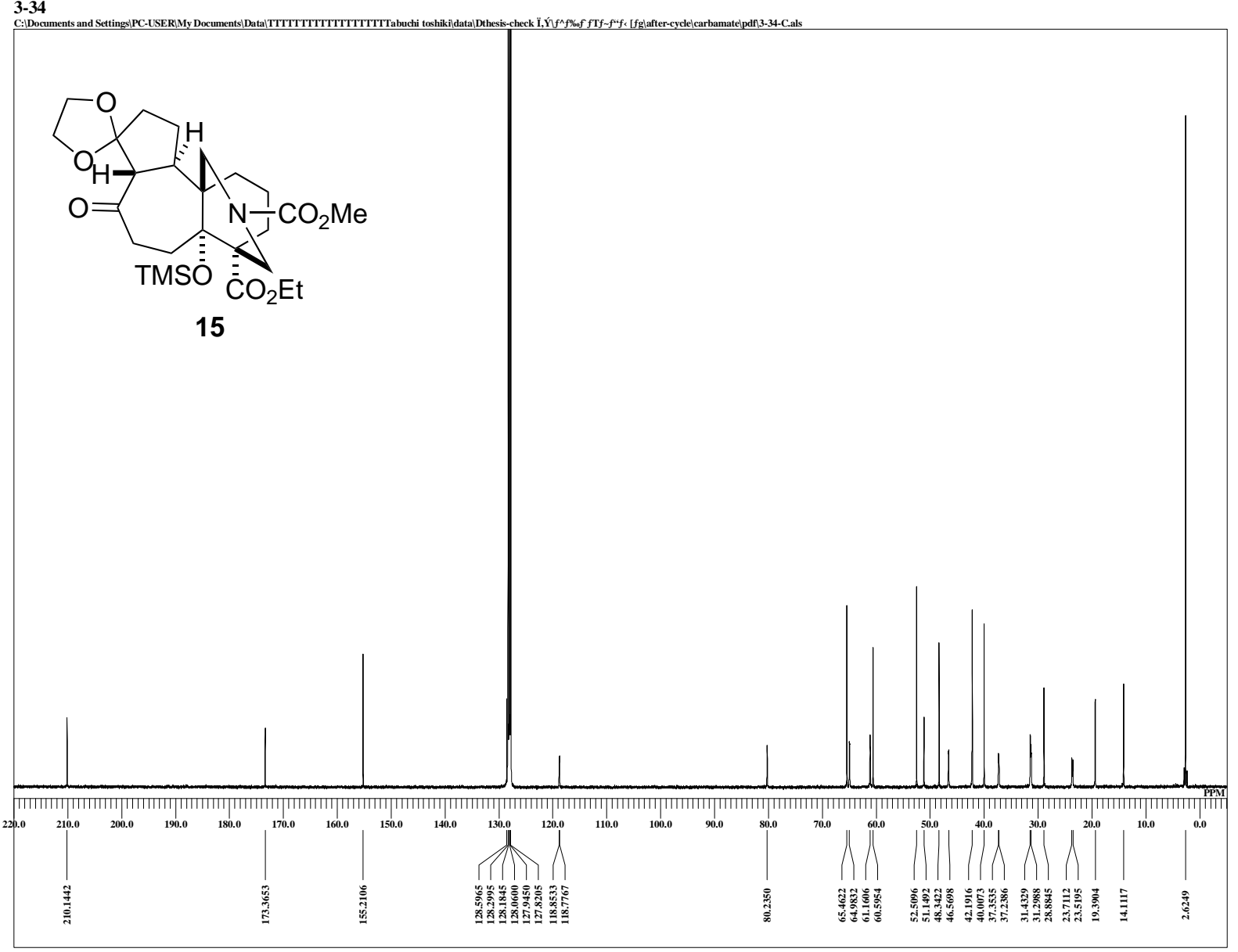


s1

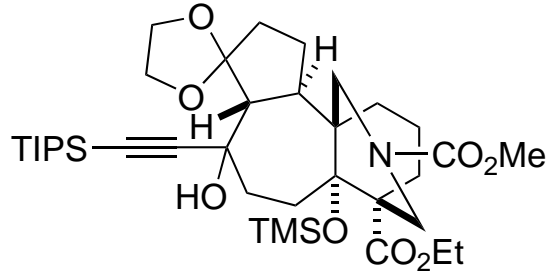

16

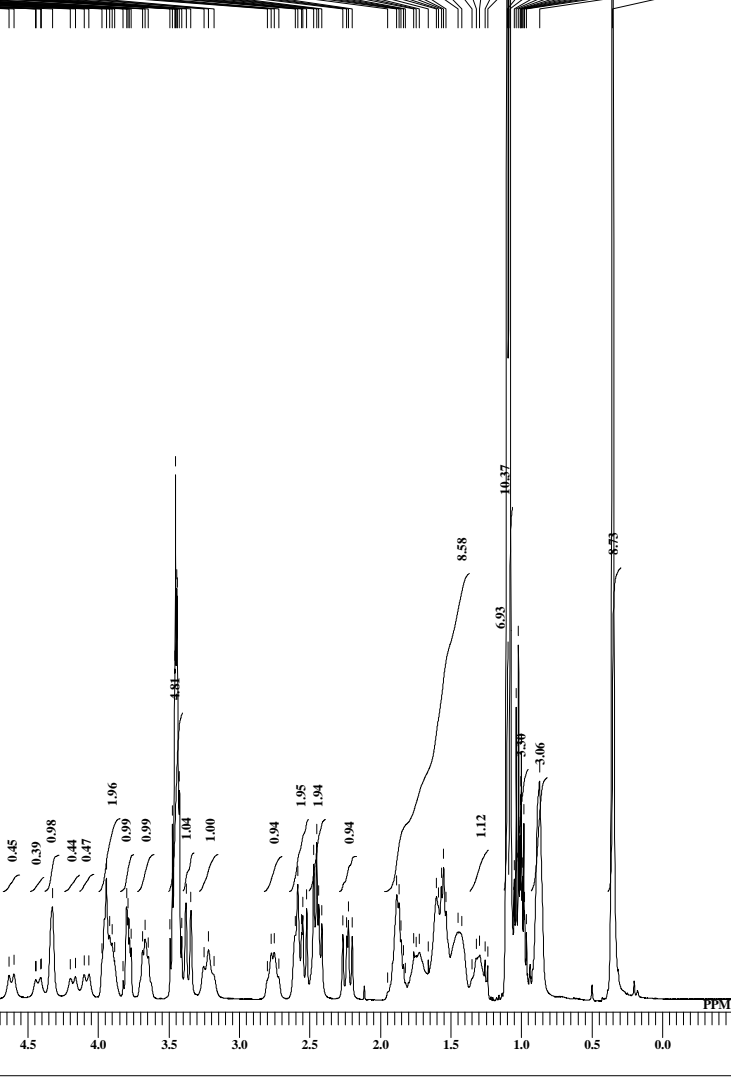

$\begin{array}{ll}\text { DFILE } & \text { S1-H.als } \\ \text { COMNT } & \text { S1 } \\ \text { DATIM } & \text { 11-11-2013 22:19:01 } \\ \text { MENUF } & \end{array}$

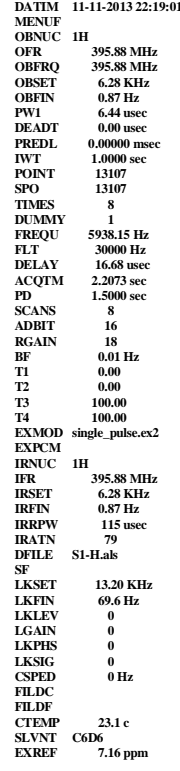

S1

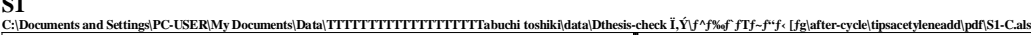
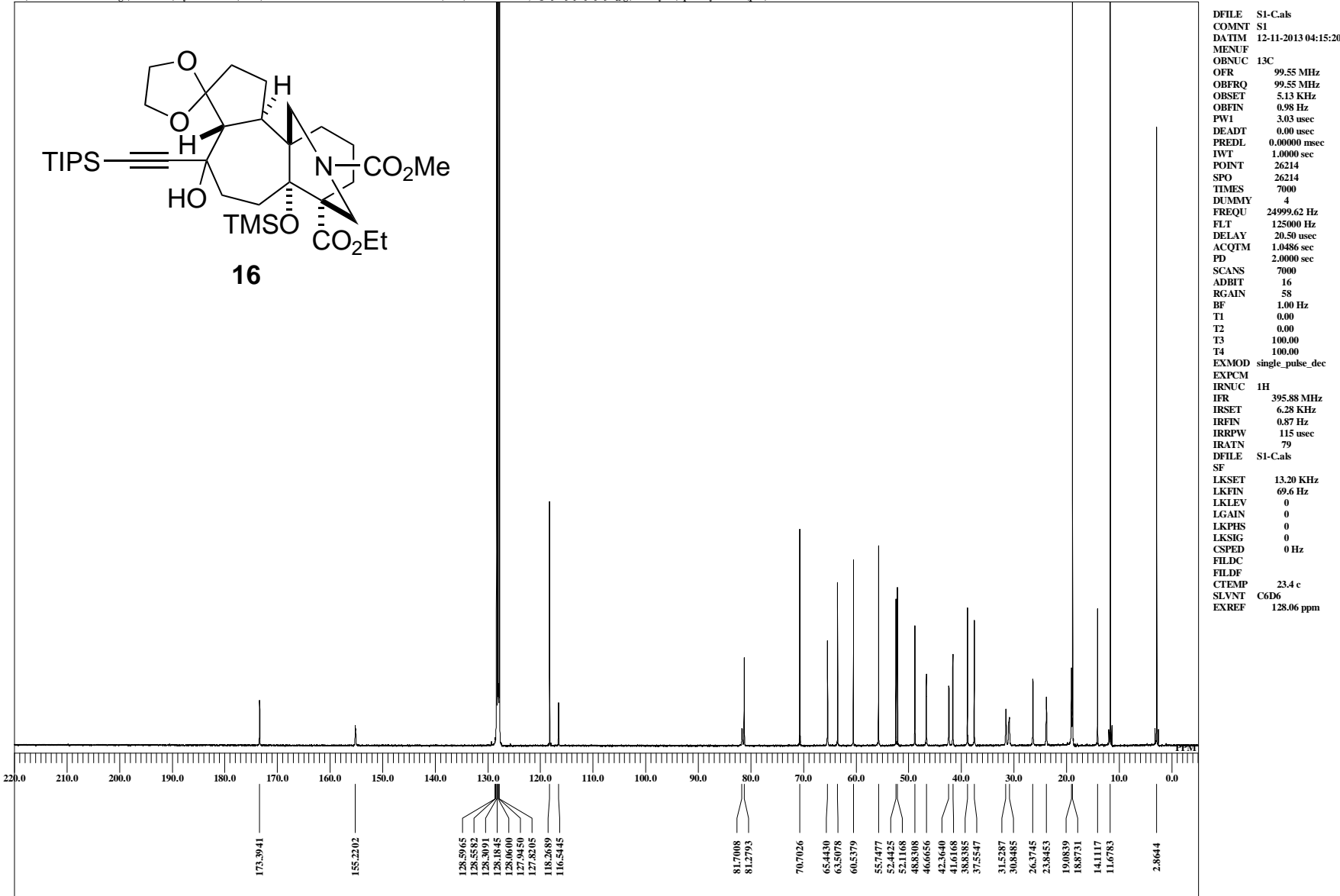
3-38b
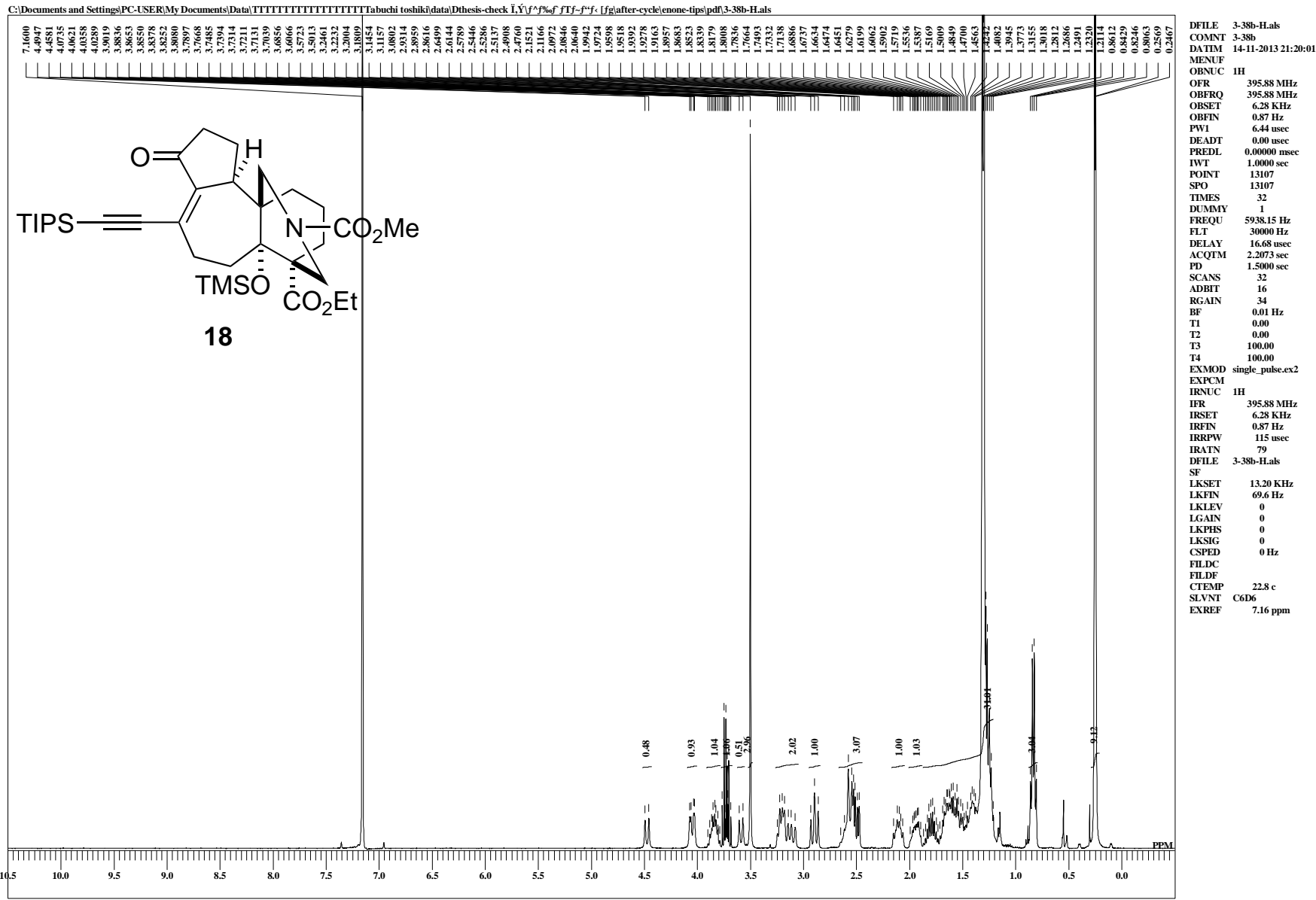

3-38b
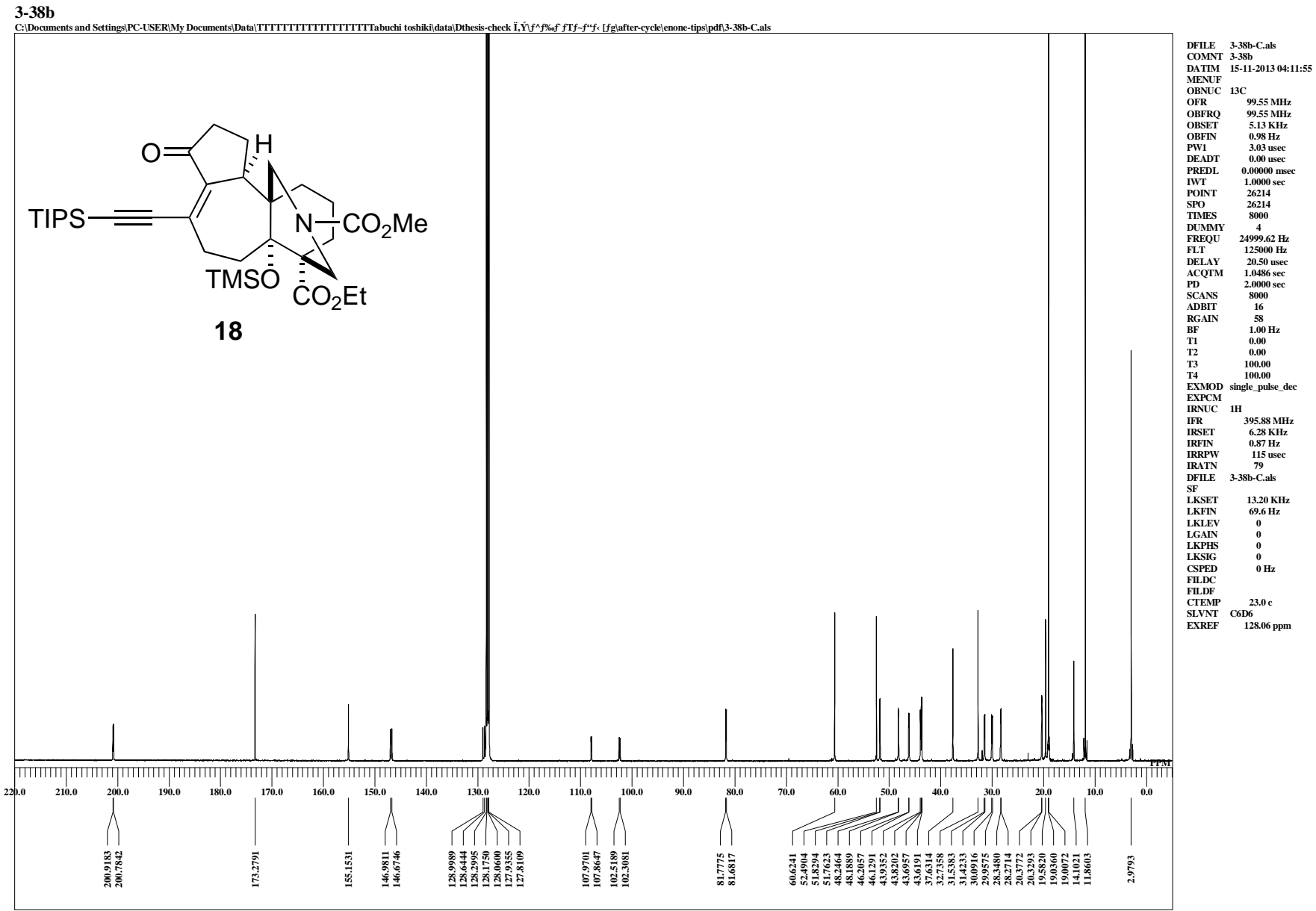
3-39b

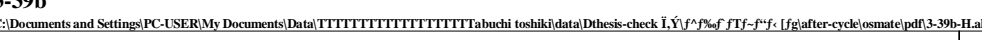

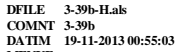

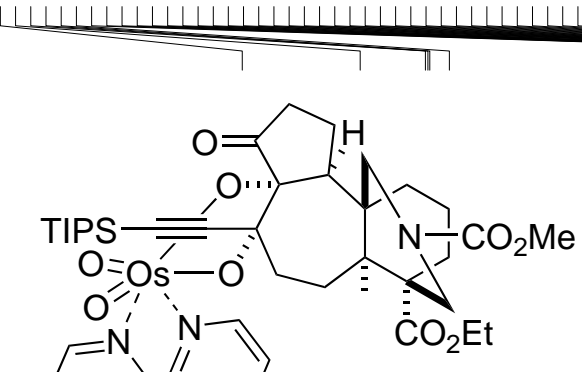

19

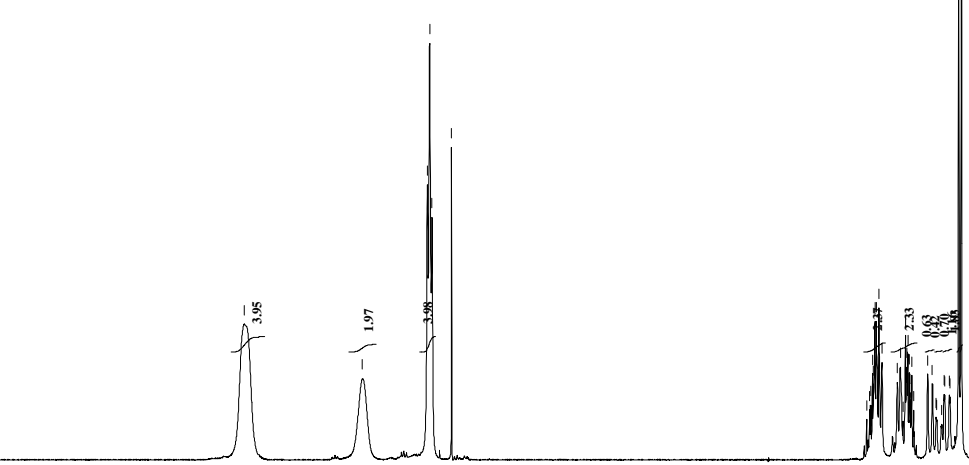

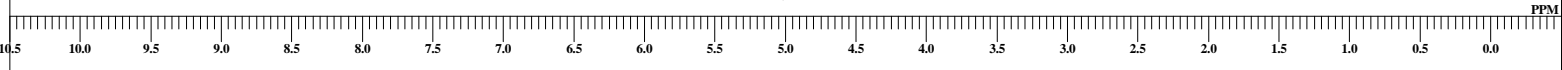

3-39b

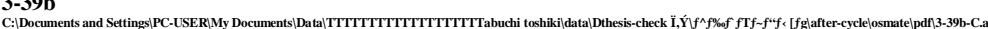

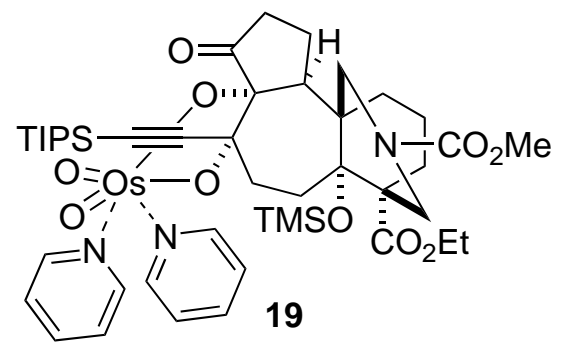

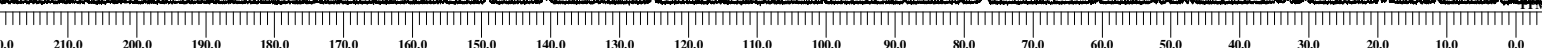

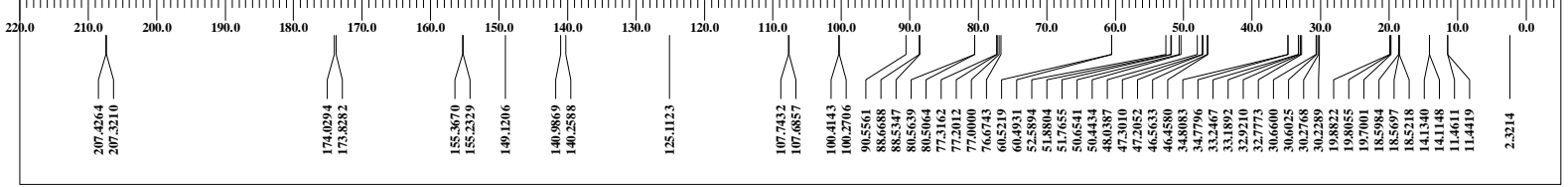


3-40b

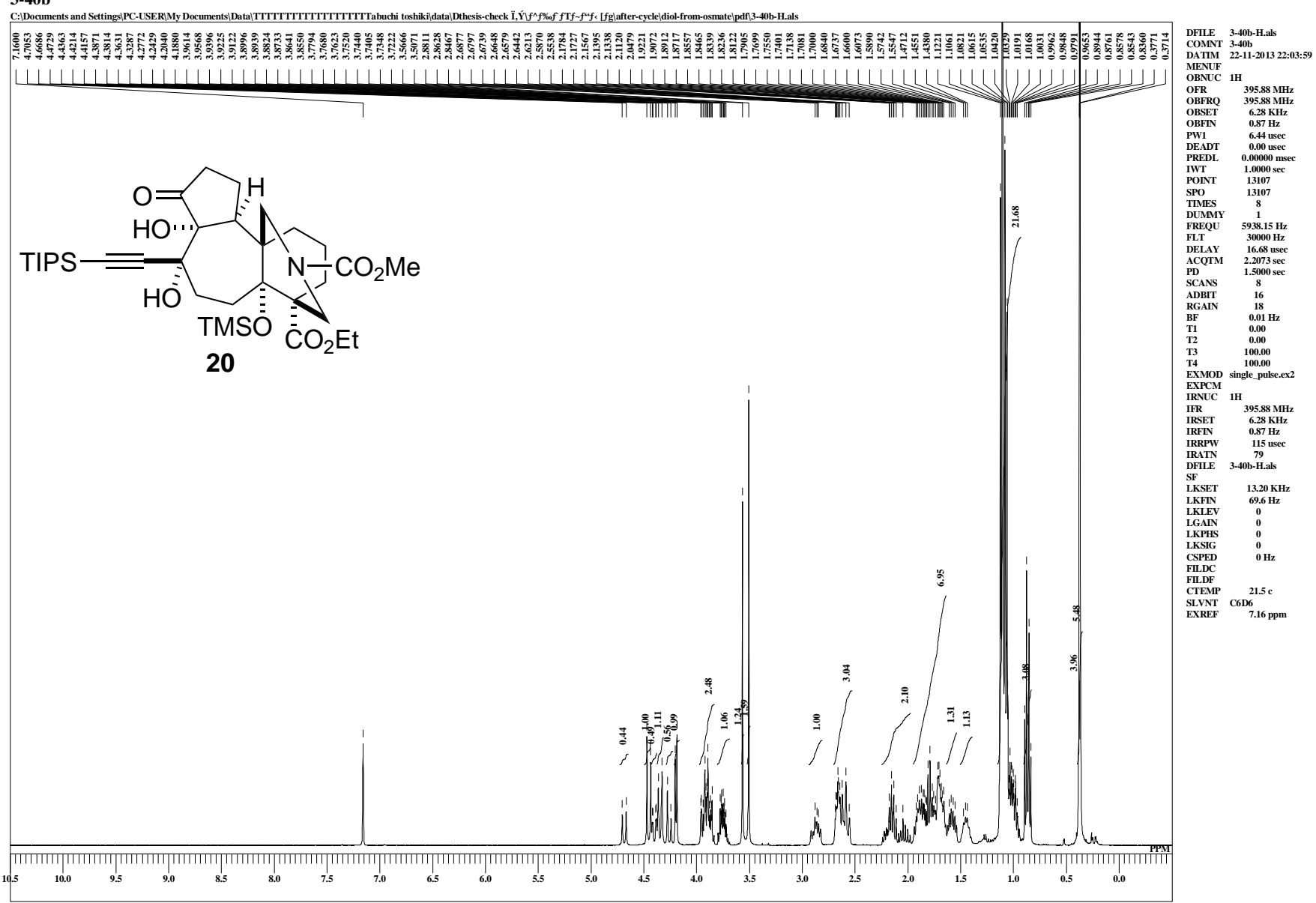

3-40b

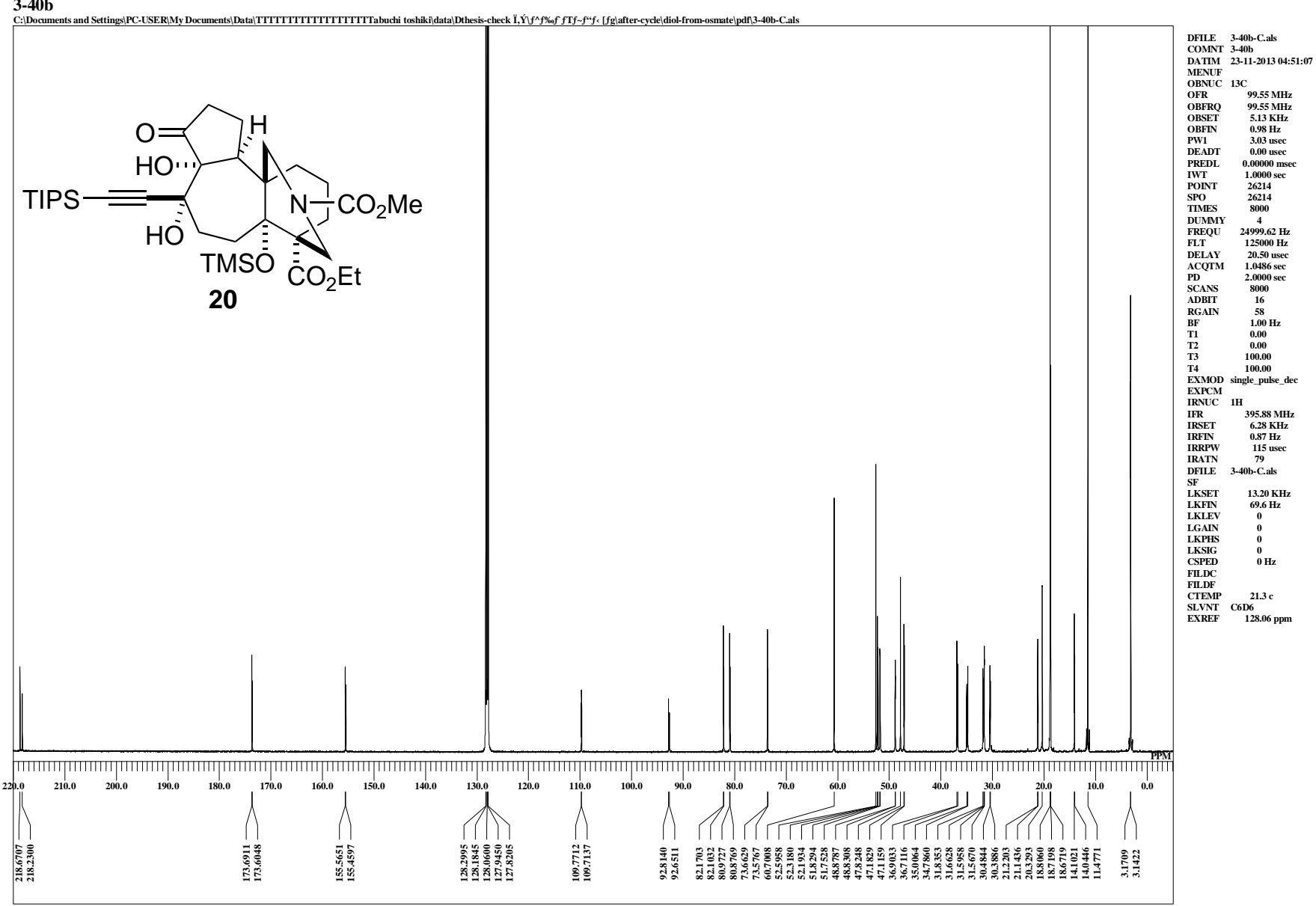


4-5

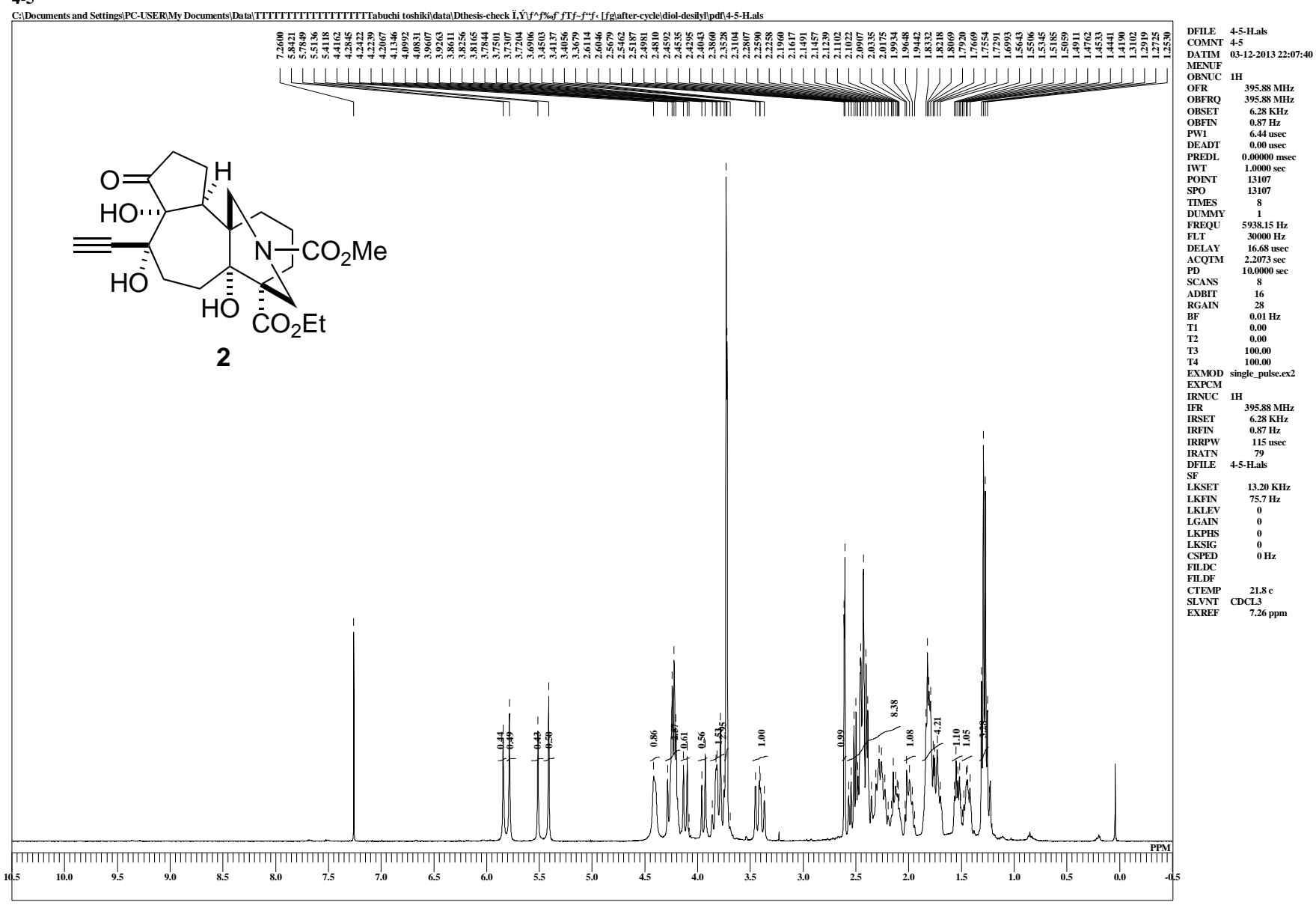

4-5

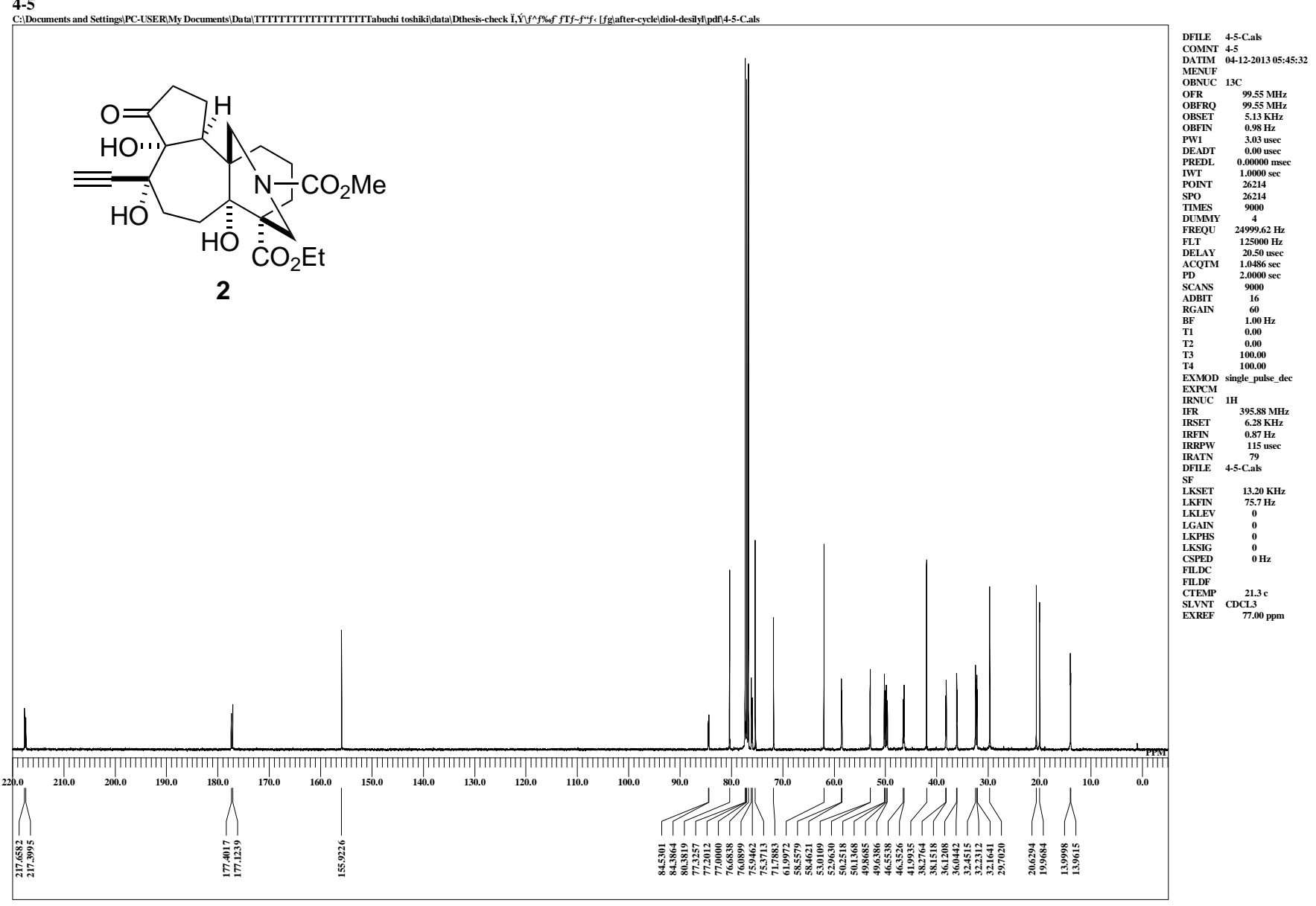


KIH-10-191-fr10-15-2
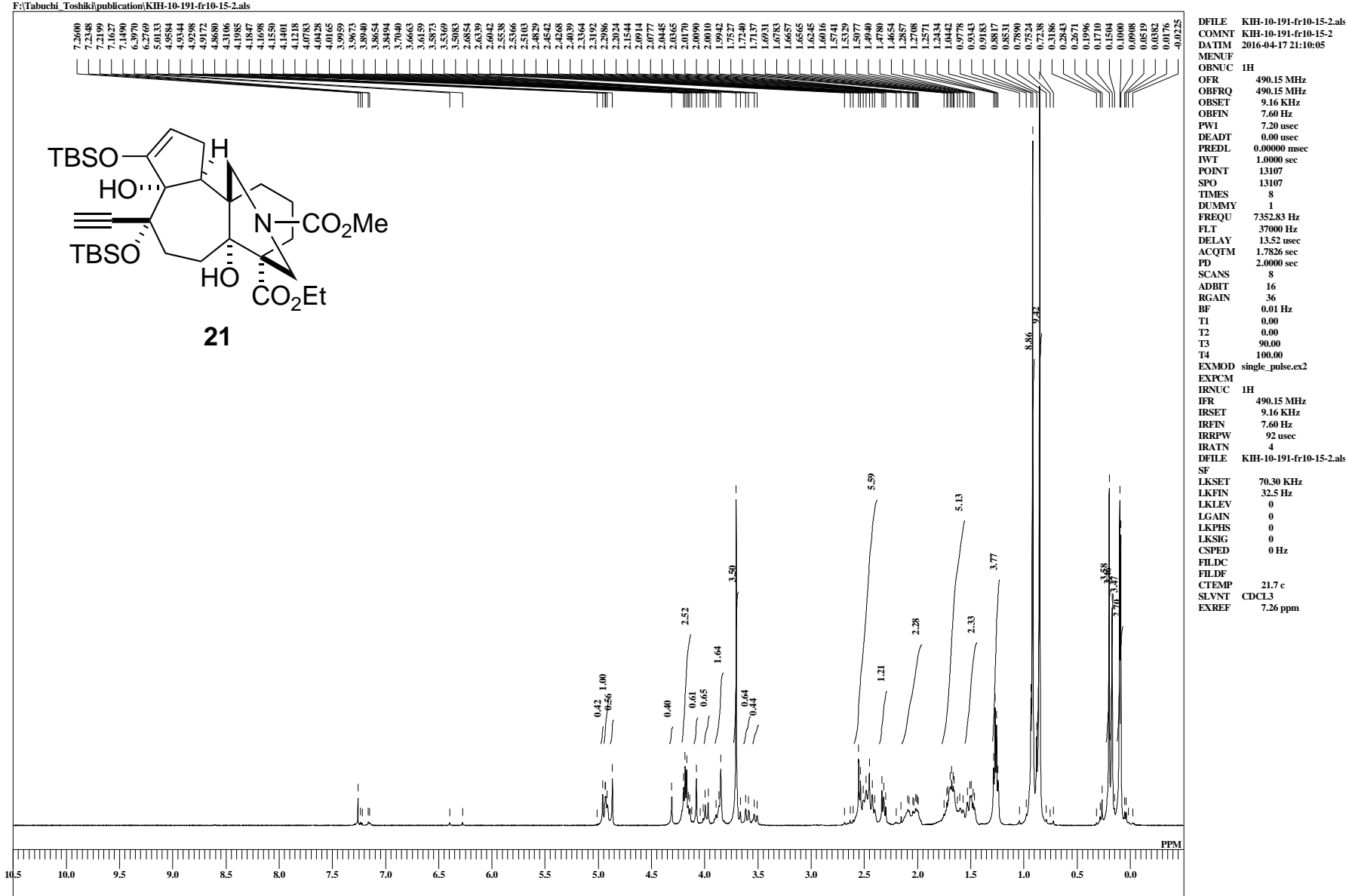

KIH-10-191-fr10-15-2-C
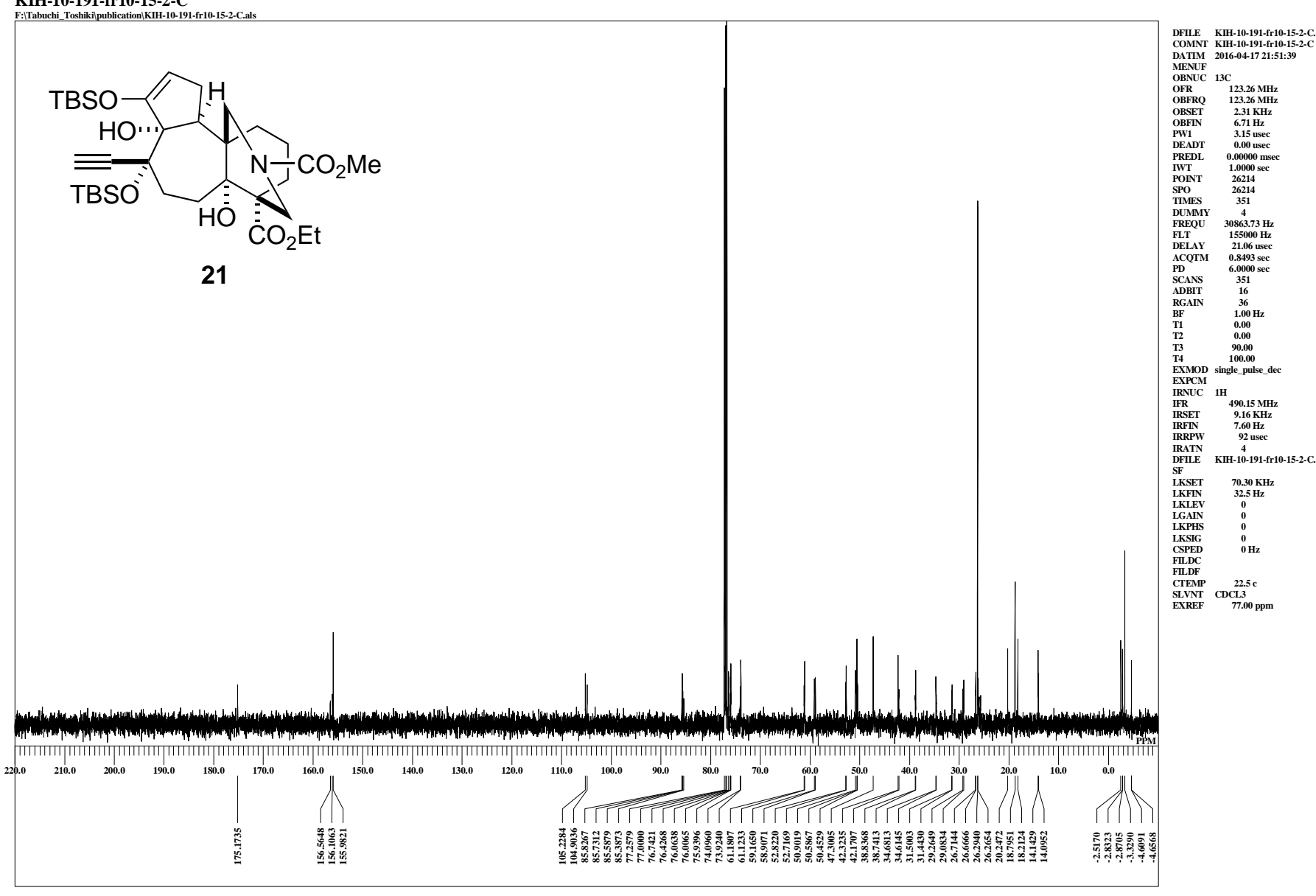


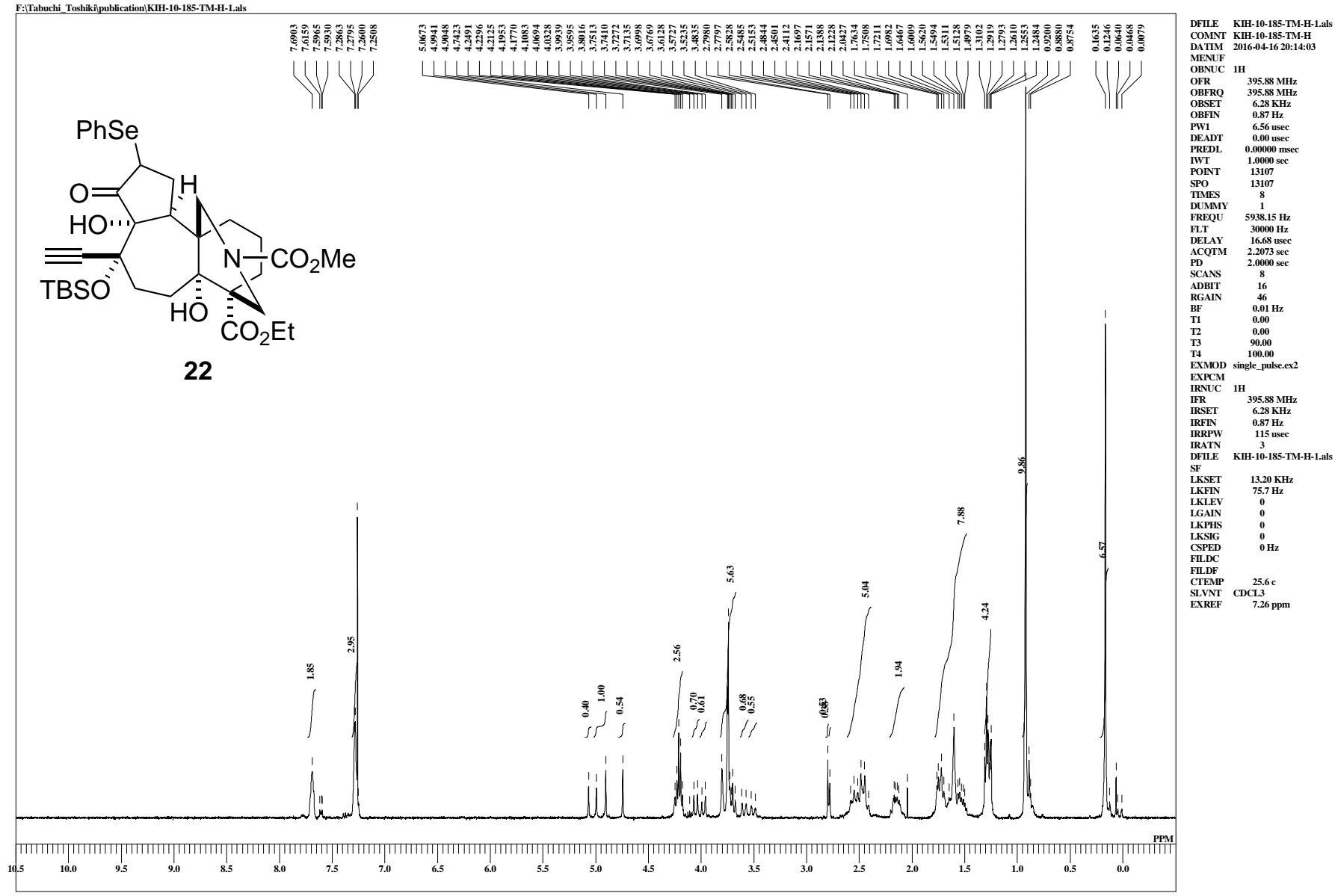

KIH-10-195-PTLC-C

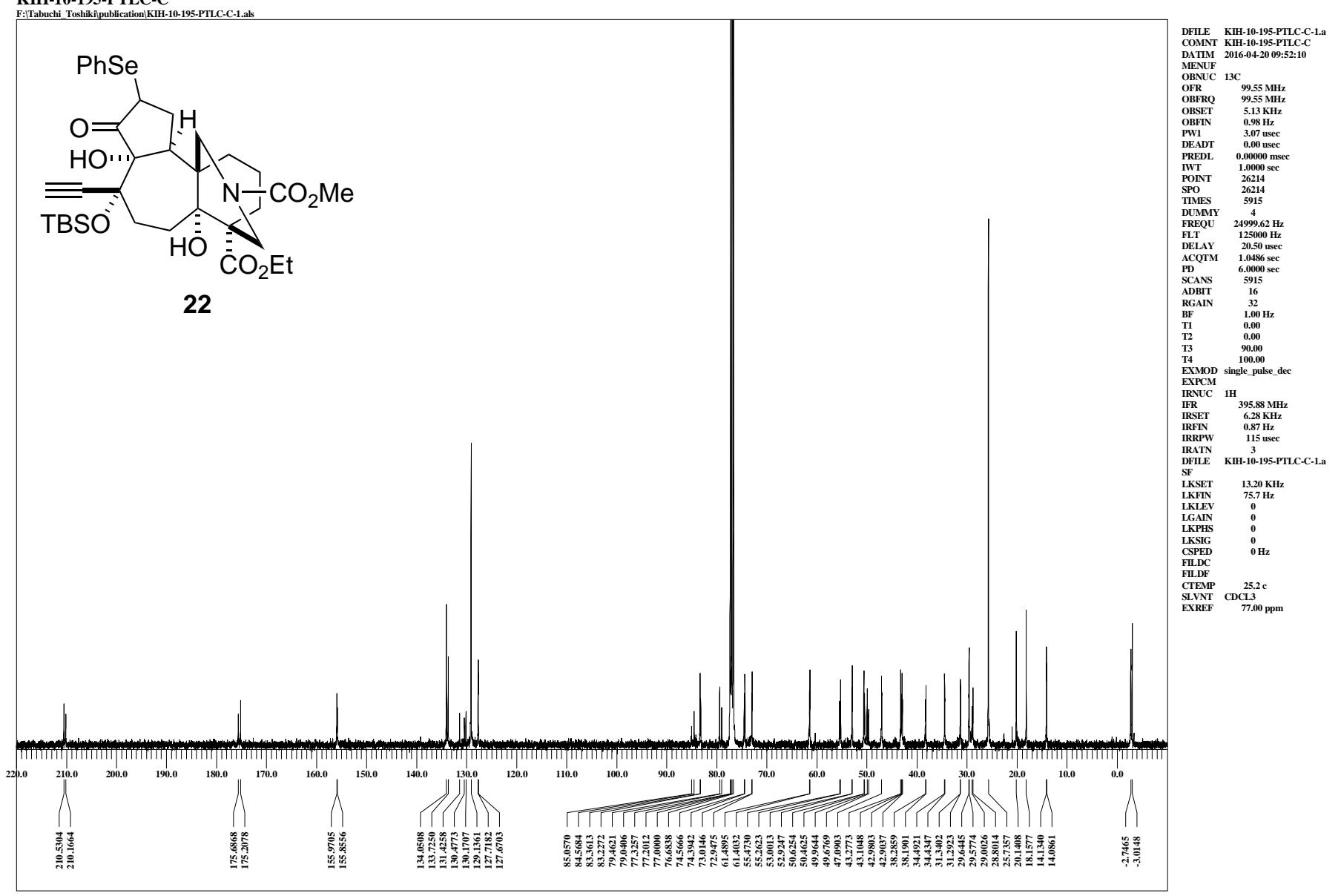


4-35

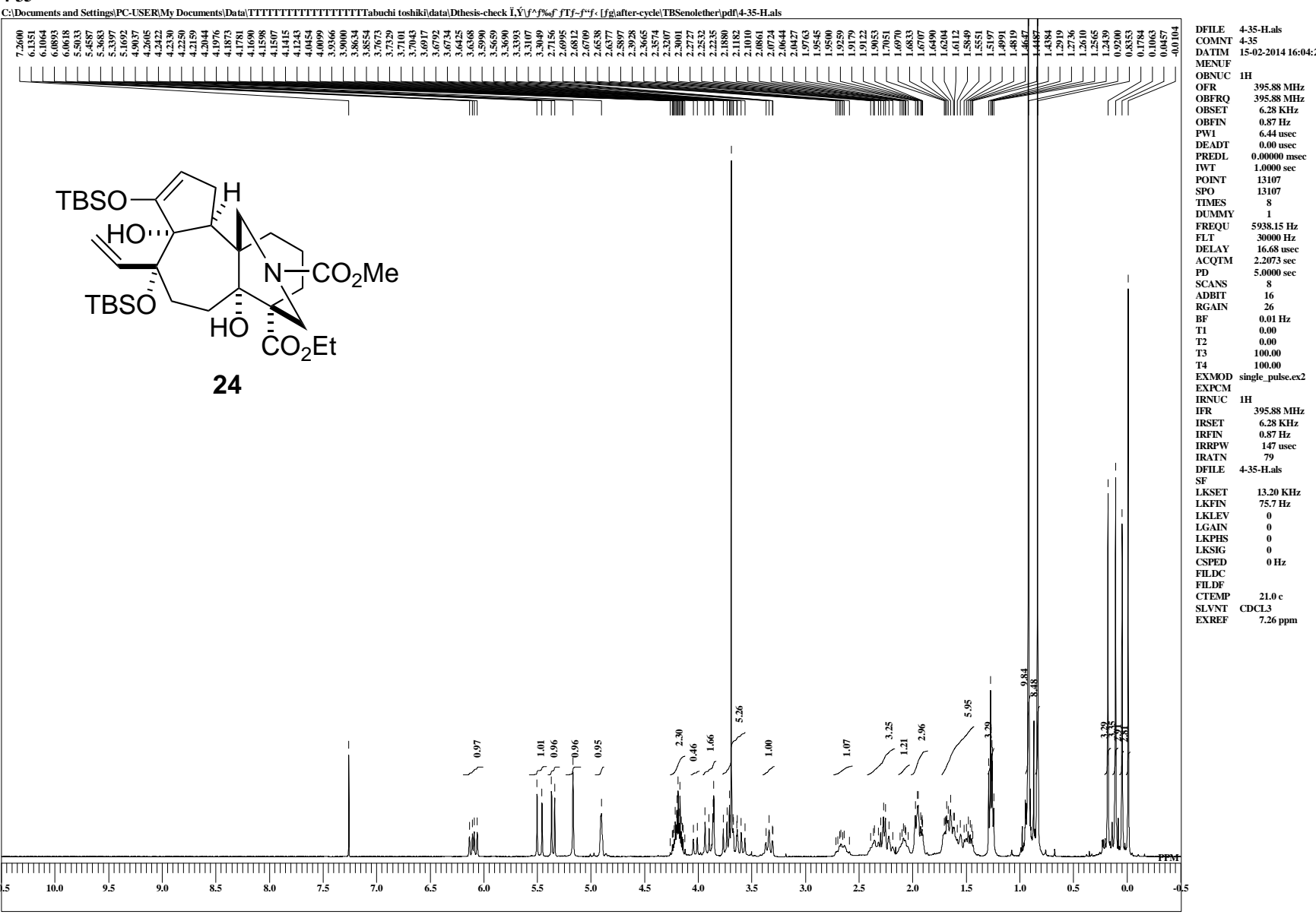

4-35

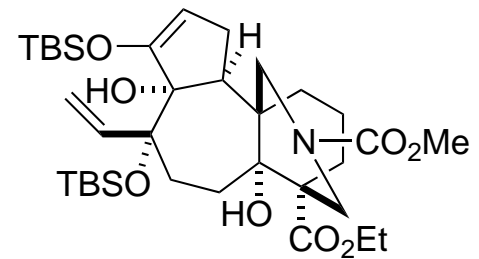

24 
4-37
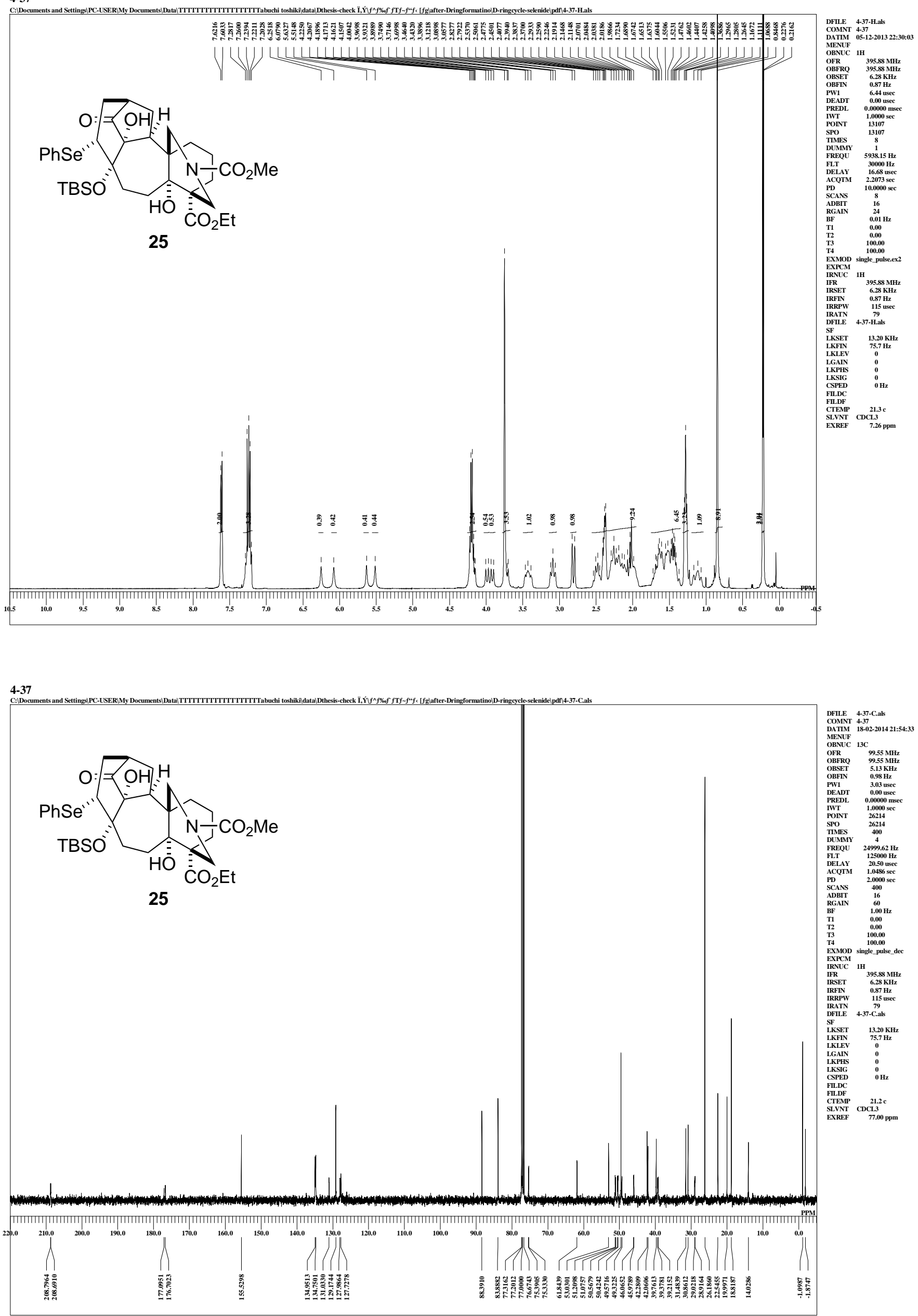


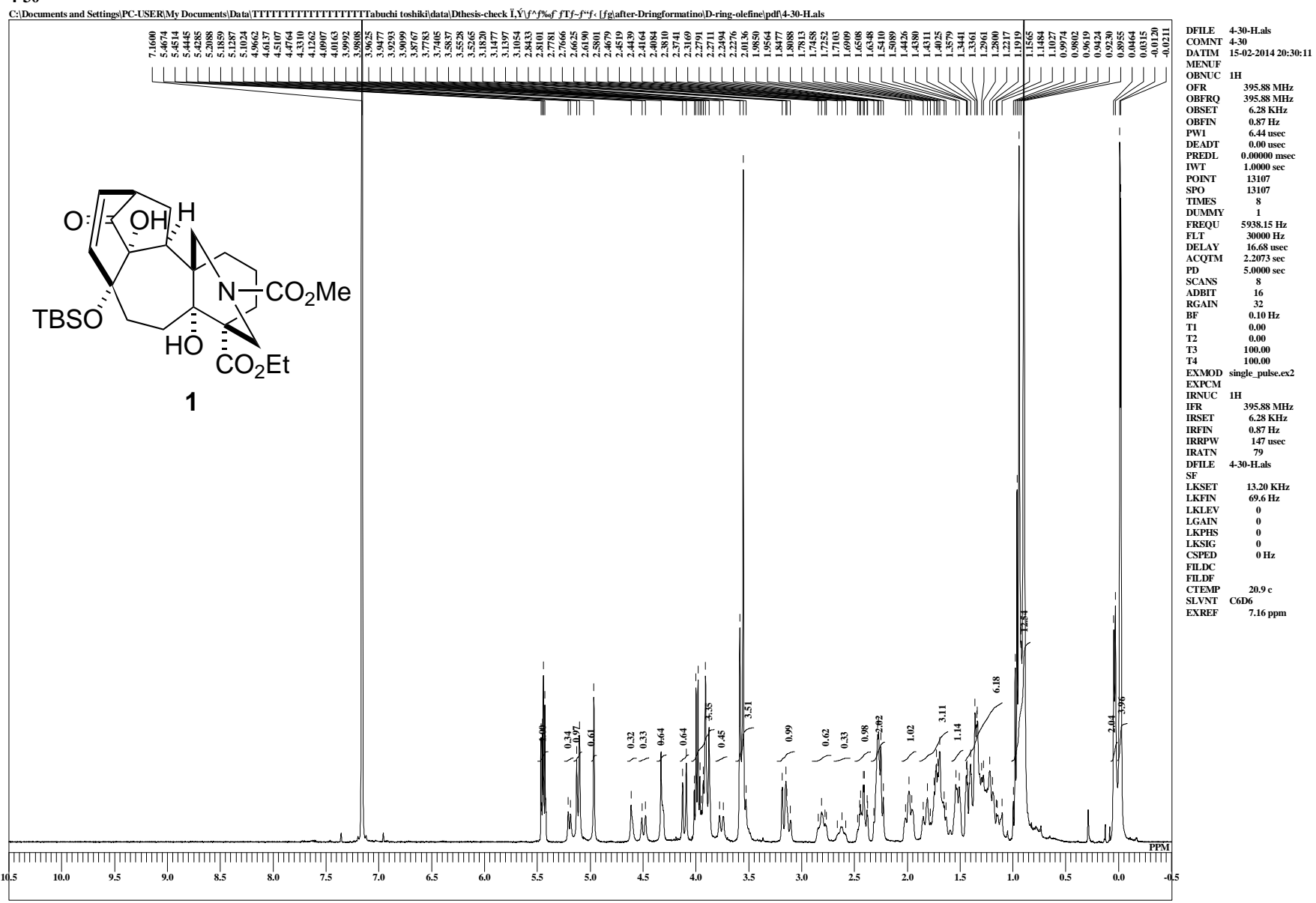

4-30

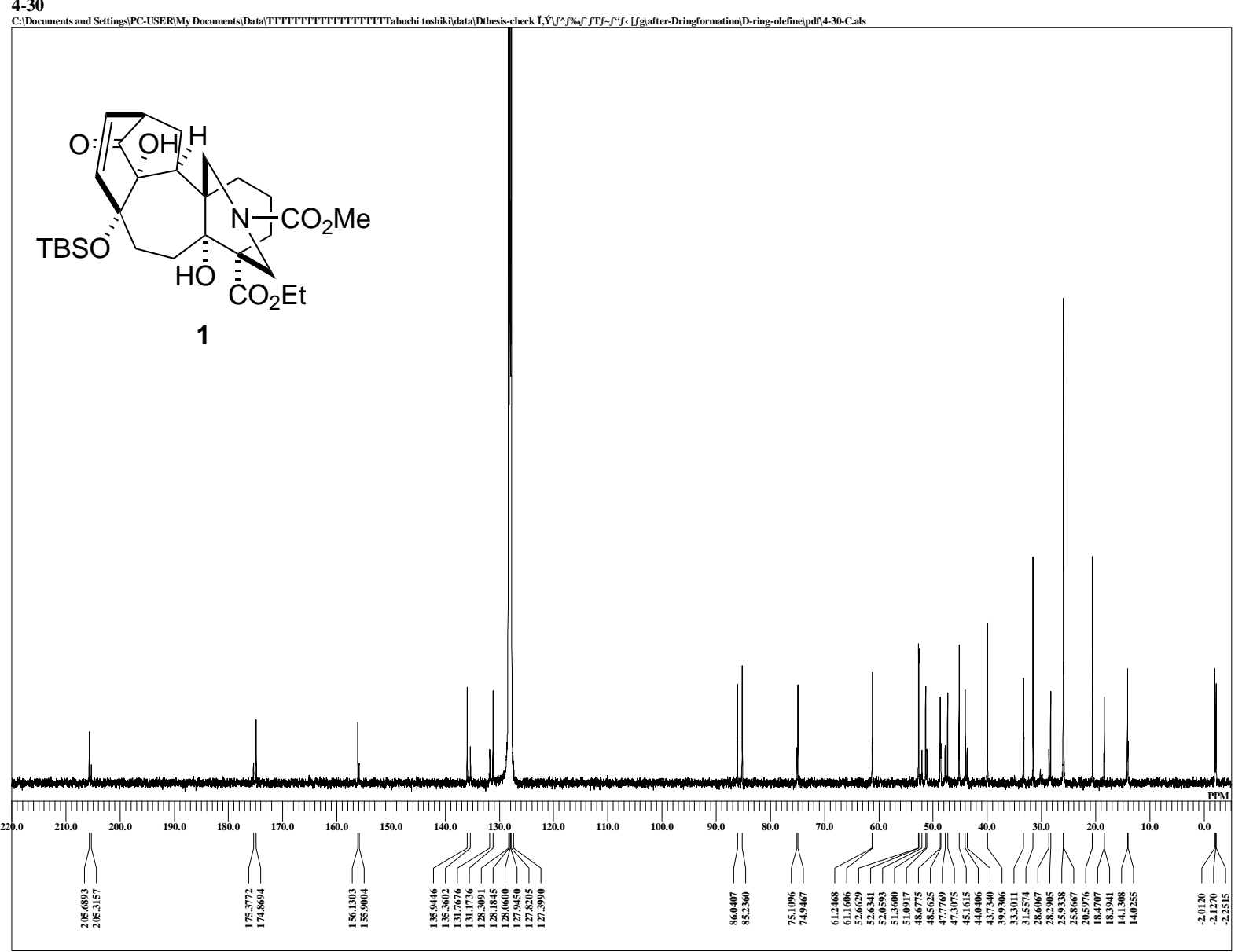




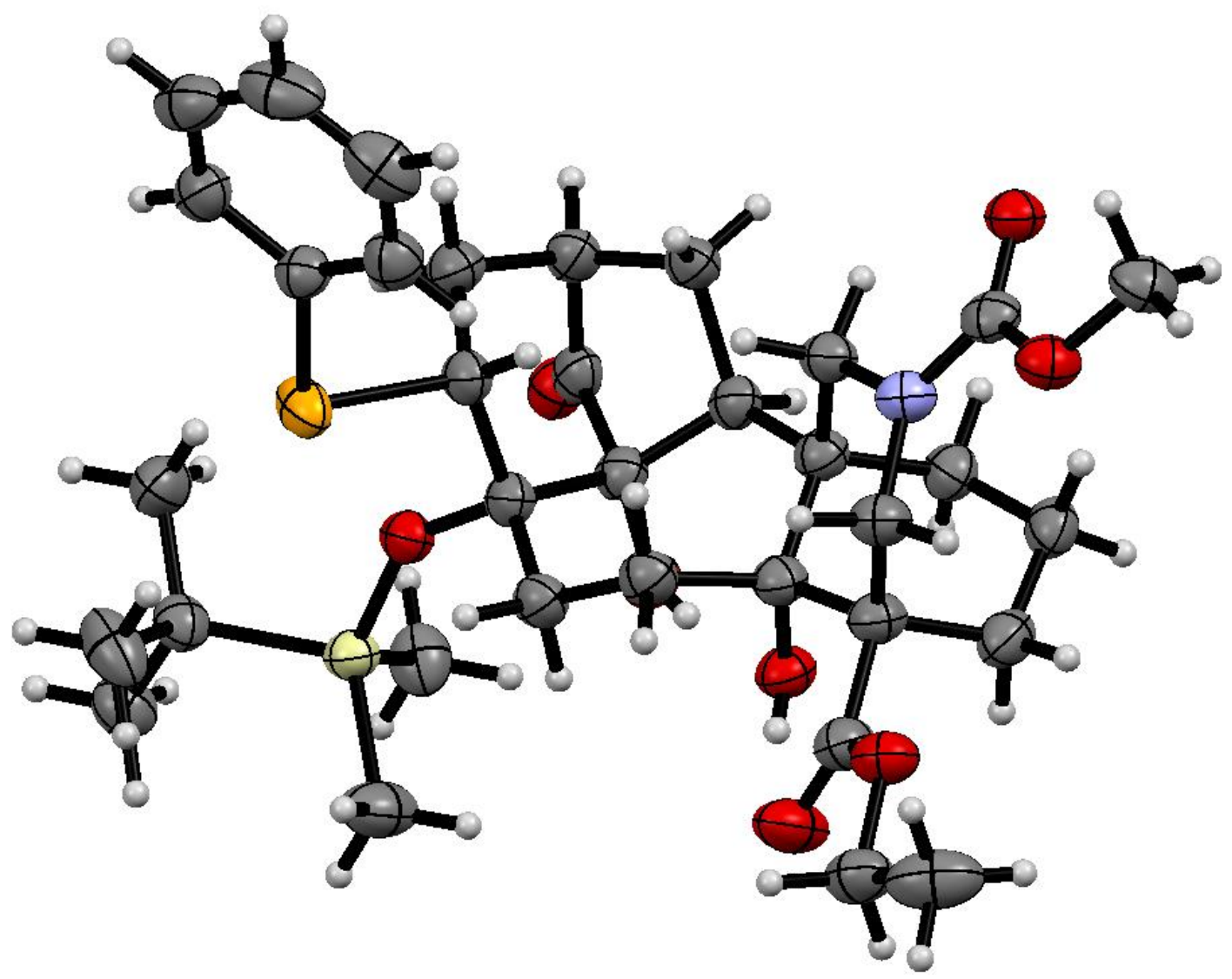

Figure S1. X-ray structure of 25 (CCDC1468828) with thermal ellipsoids at the 50\% probability level. 
Table S1. Crystal data and structure refinement for compound 25

\begin{tabular}{|c|c|}
\hline Compound & 25 \\
\hline CCDC number & 1468828 \\
\hline Molecular formula & $\mathrm{C}_{35} \mathrm{H}_{51} \mathrm{NO}_{8} \mathrm{SeSi}$ \\
\hline Formula weight & 720.82 \\
\hline Temperature (K) & $93(2)$ \\
\hline Wavelength $(\AA)$ & 1.54178 \\
\hline Crystal size $\left(\mathrm{mm}^{3}\right)$ & $0.08 \times 0.06 \times 0.04$ \\
\hline Crystal system & Monoclinic \\
\hline Space group & $P 2_{1} / \mathrm{n}$ \\
\hline \multicolumn{2}{|l|}{ Unit cell dimensions } \\
\hline $\mathrm{a}(\AA)$ & $21.0171(11)$ \\
\hline $\mathrm{b}(\AA)$ & $8.3446(5)$ \\
\hline c $(\AA)$ & $21.3332(12)$ \\
\hline$\alpha\left({ }^{\circ}\right)$ & 90 \\
\hline$\beta\left({ }^{\circ}\right)$ & $114.015(3)$ \\
\hline$\gamma\left({ }^{\circ}\right)$ & 90 \\
\hline Volume $\left(\AA^{3}\right)$ & $3417.5(3)$ \\
\hline$Z$ & 4 \\
\hline Density (calculated) $\left(\mathrm{g} / \mathrm{cm}^{3}\right)$ & 1.401 \\
\hline $\mathrm{F}(000)$ & 1520 \\
\hline \multirow[t]{3}{*}{ Index ranges } & $-25<=\mathrm{h}<25$ \\
\hline & $-9<=\mathrm{k}<9$ \\
\hline & $-25<=1<25$ \\
\hline Reflections collected & 22973 \\
\hline Independent reflections & 6026 \\
\hline $\mathrm{R}($ int $)$ & 0.0482 \\
\hline Completeness to theta & $66.74^{\circ}, 99.8 \%$ \\
\hline Max. and min. transmission & $0.78,0.92$ \\
\hline Refinement method & Full-matrix least-squares on $\mathrm{F}^{2}$ \\
\hline No. Observations (All reflections) & 6026 \\
\hline No. Variables & 488 \\
\hline Reflection/Parameter Ratio & 12.3 \\
\hline Goodness-of-fit on $\mathrm{F}^{2}$ & 1.021 \\
\hline Residuals: R1 $(I>2.00 \sigma(I))$ & 0.0482 \\
\hline Residuals: R (All reflections) & 0.0633 \\
\hline Residuals: wR2 (All reflections) & 0.1381 \\
\hline Max. and min. peak in Final Diff. Map $\left(\mathrm{e}^{-} / \AA^{3}\right)$ & $0.639,-0.749$ \\
\hline
\end{tabular}

